Research Article

\title{
The Influence Mechanism of the Master Weak Interlayer on Bench Blasting Effect and Its Evaluation Method
}

\author{
Senlin Nan $\mathbb{D}^{1,2}$, Weiming Guan ${ }^{10},{ }^{1,2}$ Tao Hu, ${ }^{3}$ Weisheng Shi, ${ }^{4}$ Junhui Zhang $\left(\mathbb{D},{ }^{1,2}\right.$ \\ Hui Chen, ${ }^{1,2}$ Junyu Cong, ${ }^{5}$ and Huabin Liu $\mathbb{D}^{1,2}$ \\ ${ }^{1}$ College of Geology and Mines Engineering, Xinjiang University, Urumqi 830047, China \\ ${ }^{2}$ Autonomous Region Experimental Teaching Demonstration Center for Geology and Mining Engineering, Xinjiang University, \\ Urumqi 830047, China \\ ${ }^{3}$ XinJiang Coal Design and Research Institute Co., Ltd., Urumqi 830091, China \\ ${ }^{4}$ Gezhouba Yipuli Xinjiang Blasting Engineering Co., Ltd., Urumqi 830046, China \\ ${ }^{5}$ GDEM Technology Beijing, Co., Ltd., Beijing 100096, China
}

Correspondence should be addressed to Weiming Guan; gwmxju@xju.edu.cn

Received 13 May 2021; Accepted 2 July 2021; Published 13 July 2021

Academic Editor: Wu Cai

Copyright (c) 2021 Senlin Nan et al. This is an open access article distributed under the Creative Commons Attribution License, which permits unrestricted use, distribution, and reproduction in any medium, provided the original work is properly cited.

The weak interlayers in an open-pit blasting bench affect the uniform distribution of explosive energy. To explore the mechanistic influence of a weak interlayer on the effect of blasting, 9 sets of numerical blasting experiments were constructed using the orthogonal experiment method. The degree of bench crushing after blasting, the maximum velocity of the rock mass at $0.05 \mathrm{~s}$, and the displacement of the back of the bench were thus investigated. The analysis revealed that the impact of the thickness of the weak interlayer, its wave impedance, and its location of occurrence on the bench blasting indicated an ordered decreasing effect. Based on this, the evaluation method for the master weak interlayer and the design plan of the specific charge structure were proposed. The evaluated design proposals were verified through both numerical and field tests. The research results will provide a scientific basis to determine a reasonable charge structure of the bench blasting of rock masses containing weak interlayers.

\section{Introduction}

China is a country with more coal and less oil, with its coal output ranked first in the world for many years $[1,2]$. Xinjiang is rich in coal resources, with predicted coal reserves ranging from 1.82 to 2.19 trillion tons, accounting for $43 \%$ of the country's total predicted reserves $[3,4] .80 \%$ of Xinjiang's coal production capacity is supplied by open-pit coal mines [5, 6]. However, open-pit coal mines in Xinjiang often have interbedded, alternating, soft, and hard rock mass strata $[7,8]$. In such a scenario, the blasting energy is unevenly distributed in the rock body and is easily facilitated to leak along with the weak layer [9]. This eventually causes undesirable blasting effects such as a boulder, back-pulling, and flying rock hazards [10]. As a result, the efficiency of excavation and transportation is low, the cost of secondary treatment soars high [11], the safety risks become paramount, and it also facilitates adverse consequences such as geological disasters [12].

A weak interlayer refers to a rock layer with low mechanical strength, long extension, and a certain thickness sandwiched between hard rock layers [13, 14]. Scholars have studied the blasting technology and mechanism of layered rock masses for a long time and have drawn many conclusions. Zeinab et al. have reported the extension behavior of cracks in layered rock masses $[15,16]$. Jong et al. have given the criterion of the specific crack propagation direction and proposed the calculation methods for the crack length [17, 18]. Song et al. had clarified the response characteristics of weak interlayer under blasting $[19,20]$, and Sen et al. proved that weak interlayer is an important factor affecting the distributio of stress waves [21, 22]. Kaide et al. summarized the deformation mechanism of soft and hard interbedded strata under external forces [23, 24], while Song 
et al. investigated the influence of interbedded rock mass on blasting vibration $[25,26]$. Wang et al. clarified the influence of charge position on the bedding sliding of the weak interlayer [27]. Liu et al. constructed a new evaluation method of bench blasting effect [28]. Through field tests, Bui et al. have studied how to use artificial intelligence methods to predict the influence of blasting vibration on the surrounding area [29, 30].

Through a large number of scholars' studies, it is evident that the main reason for the poor blasting effect in this type of rock mass stratification is that any weak interlayer in the rock mass changes the propagation path of the blast stress wave, resulting in excessive energy directed to the weak interlayer while diminishing the desired effect on the hard rock. Existing studies have also indicated that the strategic way to solve the above problems is to change the charging structure of the blast hole and use methods such as linear density difference or interval charging to reduce the adverse influence from the master weak stratum. The most important thing in the application of these methods is the need to accurately understand the location, overall occurrence, and local engineering geological characteristics of this weakest interbedded stratum in the blasting bench. Subsequently, the specific blasting parameters can be designed accordingly. However, in the actual open-pit mine situation, a rock mass bench containing one or more weak interlayers with little difference in mechanical properties is often encountered. Such occurrence makes it difficult to determine the position of the master weak interlayer in the rock mass. Therefore, there is an urgent need for a quick and ready procedure to identify the position of the master weak interlayer in the rock mass bench. The master weak interlayer in this article refers to the interlayer that has the greatest influence on the blasting effect from all the strata in the rock mass bench.

In response to finding a solution to the above problems, this article intends to clarify the fundamental properties and mechanisms of weak interlayers that affect the blasting effect. Starting from the influence of different weak interlayer properties on the bench blasting effect based on previous studies, in combination with the principle of the change of the master weak interlayer to the minimum resistance line. A master weak interlayer evaluation was constructed, which considered weak interlayer thickness and wave impedance, etc., providing a scientific basis for the design of bench blasting for an interbedded stratum.

\section{The Influence of Weak Interlayer on the Effect of Blasting}

To investigate the influence of weak interlayers on the effect of blasting, this paper used numerical analysis to simulate the blasting process under different conditions. The objective was to find out the main factors that affect the blasting effect and the relationship between the main factors and the blasting effect.

2.1. Design of Experiment. The thickness, the height from the chassis, the inclination angle, and the physical characteristics of the weak interlayer in the blasting bench were the main changing factors. The inclination angle of the layering and the blast hole were either perpendicular or oblique. This reflected on the axial section of the blast hole with the relationship between the thickness of the sandwich and the height from the chassis. Therefore, the research model was a horizontal interlayer. The influencing factors were the thickness $T$ of the interlayer, the height $\mathrm{H}$ from the center of the interlayer to the chassis, and its wave impedance $R$ (the product of rock density and longitudinal wave velocity).

Orthogonal experimental design is a design of experiment method that studies multiple factors and levels. It selects some representative points from all experiments based on orthogonality to conduct the experiments. This bears the characteristics of being evenly dispersed, neat, and comparable. The experiment has 3 set levels for each of the above 3 elements, resulting in 9 experimental schemes according to the orthogonal table (Table 1) and the combination of each element is shown therein.

2.2. Evaluation Method of Blasting Effect. To quantitatively evaluate the blasting effect in the experiment, this article uses the following 3 indicators: (1) boulder yield: according to the specifications of the on-site scraper, this article judged the block with the largest size greater than $2 \mathrm{~m}$ in boulder yield. A higher volume fraction of boulder fragments indicated an adverse blasting effect. (2) Flying rock: based on the maximum velocity $V$ of the rock mass in the bench at $0.05 \mathrm{~s}$ after the detonation, a larger value of $V$ implied a higher probability of flying rock hazards. This gives rise to a lower blasting safety. (3) Back-pulling: the displacement of point $D$ at the back edge of the bench (see Figure 1) was used to evaluate the back-pulling of the blasting bench. The greater this displacement, the more serious the impact on the subsequent working area, and thus creating an adverse blasting effect.

The specific steps for the comprehensive evaluation of the blasting effect were as follows. First, the blasting effects from the 9 schemes were scored using the same indicator with a full score of 9 . A higher score indicated a better blasting effect. Second, the scores of each scheme under three different evaluation indicators were added to obtain the $M$ value. Thirdly, the $M$ values from the 9 schemes were sorted from large to small. The scheme with a smaller ranking indicated a better comprehensive blasting effect.

\subsection{Design of the Numerical Model}

2.3.1. Geometric Characteristics of the Model. The model was designed with one blast hole, which detonated from the center of the grain, as shown in Figure 1. The size of the model was as follows: the length in the $x$-direction was $20 \mathrm{~m}$, the length in the $y$-direction was $20 \mathrm{~m}$, the bench height was $10 \mathrm{~m}$, and the slope was $75^{\circ}$. Points $A, B$, and $C$ were the velocity monitoring points, and point $D$ was the displacement monitoring point. The design was carried 
TABLE 1: Orthogonal experiment scheme of weak interlayer's influence on bench blasting effect.

\begin{tabular}{lccc}
\hline Factor & Thickness $(\mathrm{m})$ & Height $(\mathrm{m})$ & Wave impedance $\left(10^{6} \cdot \mathrm{kg} /\left(\mathrm{m}^{2} \cdot \mathrm{s}\right)\right)$ \\
\hline Experiment 1 & 0.5 & 1.5 & 1.88 \\
Experiment 2 & 0.5 & 3 & 3.87 \\
Experiment 3 & 0.5 & 4.5 & 5.24 \\
Experiment 4 & 1.5 & 1.5 & 3.87 \\
Experiment 5 & 1.5 & 3 & 5.24 \\
Experiment 6 & 1.5 & 4.5 & 1.88 \\
Experiment 7 & 2.5 & 1.5 & 5.24 \\
Experiment 8 & 2.5 & 3 & 1.88 \\
Experiment 9 & 2.5 & 4.5 & 3.87 \\
\hline
\end{tabular}

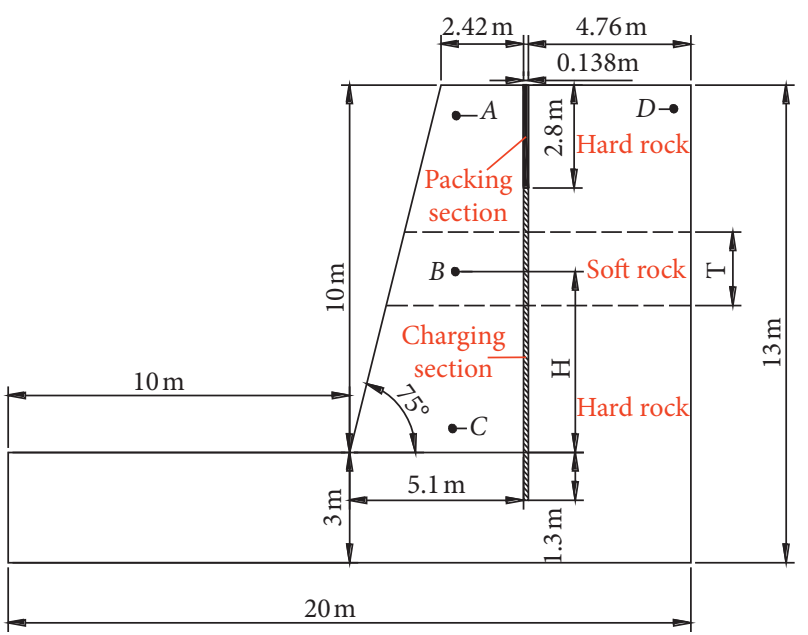

FIGURE 1: Schematic diagram of the geometry of the numerical model.

TABLE 2: Design parameters of the numerical blasting model.

\begin{tabular}{lcccc}
\hline Drilling diameter $d(\mathrm{~mm})$ & Hole distance, $a(\mathrm{~m})$ & Overdrilling depth, $h(\mathrm{~m})$ & Drilling depth, $L(\mathrm{~m})$ & Packing length, $l_{d}(\mathrm{~m})$ \\
\hline 138 & 2.42 & 1.3 & 11.3 & 2.8 \\
\hline
\end{tabular}

out according to the bench blasting design specification, and the specific parameters used are shown in Table 2.

2.3.2. Experiment Parameter Settings. The GDEM software, which was jointly developed by the Joint Laboratory of Discontinuous Medium Mechanics and Engineering Disasters of the Chinese Academy of Sciences and GDEM Technology Beijing, Co., Ltd., was used to numerically analyze the blasting. Table 3 gives the material parameters used for the blasted rock mass. The mechanical constitutive model followed the Mohr-Coulomb criterion.

At present, emulsion explosive is used in the blasting field of an open-pit mine, and almost no other explosive is used. In order to make the numerical experiment closer to the actual situation, the explosive used in this paper is an emulsion explosive. The parameters of emulsion explosives used are shown in Table 4, and the JWL constitutive model was used for the explosive. The JWL state equation described the process of the explosive generating shock pressure. The relationship between pressure and specific volume in the explosive detonation process simulated by the JWL state equation is as given as follows:

$$
P_{c j}=A\left(1-\frac{\omega}{R_{1} V}\right) e^{-R_{1} V}+B\left(1-\frac{\omega}{R_{2} V}\right) e^{-R_{1} V}+\frac{\omega E_{0}}{V}
$$

where $A, B, R_{1}, R_{2}$, and $\omega$ are the parameters of the JWL state function of the explosive. $P_{c j}$ is the initial pressure, $V$ is the relative volume, and $E_{0}$ is the initial specific internal energy. See Table 4 for specific parameter settings.

To make the simulation results be represented as accurately as possible while considering factors such as reasonable calculation time and the computing power of computers, a triangular mesh was used with a unit size of $0.2 \mathrm{~m}$. Nonreflective boundary conditions were applied on the left, right, and bottom surfaces of the model that were in contact with other rock masses. Free boundary conditions were applied on other surfaces. The calculation time step was $10^{-5} \mathrm{~s}$, the output time interval was 500 steps, and the calculation termination time was $0.05 \mathrm{~s}$. The reason for choosing $0.05 \mathrm{~s}$ time after initiation to evaluate the bench blasting effect is that all explosives have played a role of crushing at the moment, and after that time, the explosive energy has only the role of throwing on the bench rock mass, 
TABle 3: Physical and mechanical properties of rock-soil used in the numerical simulation.

\begin{tabular}{lcccccc}
\hline Lithology & $\begin{array}{c}\text { Density, } \\
\rho \\
\left(\mathrm{g} / \mathrm{cm}^{3}\right)\end{array}$ & $\begin{array}{c}\text { Cohesion, } C \\
(\mathrm{MPa})\end{array}$ & $\begin{array}{c}\text { Internal friction } \\
\text { angle, } \varphi\left(^{\circ}\right)\end{array}$ & $\begin{array}{c}\text { Young's modulus, } \\
E(\mathrm{GPa})\end{array}$ & $\begin{array}{c}\text { Dynamic tensile } \\
\text { strength }(\mathrm{MPa})\end{array}$ & $\begin{array}{c}\text { Wave impedance, } \\
10^{6} \mathrm{~kg} /\left(\mathrm{m}^{2} \cdot \mathrm{s}\right)\end{array}$ \\
\hline $\begin{array}{l}\text { Surrounding } \\
\text { rock }\end{array}$ & 2.5 & 10 & 40 & 13 & 12 & 5.65 \\
Hard & 2.0 & 9 & 39.0 & 11 & 7 & 6.4 \\
Medium & 1.5 & 1 & 38 & 2 & 3.3 & 3.24 \\
Soft & 1.0 & 0.36 & 35.0 & & 7.87 \\
\hline
\end{tabular}

TABLe 4: Material parameters of the emulsion explosive material and state parameters of the JWL equation.

\begin{tabular}{lccccccccc}
\hline Density, $\rho\left(\mathrm{kg} / \mathrm{m}^{3}\right)$ & Detonation velocity, $D(\mathrm{~m} / \mathrm{s})$ & Denotation pressure, $P_{C J}(\mathrm{GPa})$ & $A(\mathrm{GPa})$ & $B(\mathrm{GPa})$ & $R_{1}$ & $R_{2}$ & $\omega$ & $E_{0}(\mathrm{GPa})$ \\
\hline 1150 & 5000 & 7.4 & 214.4 & 0.182 & 40.2 & 00.9 & 0.15 & 4.192 \\
\hline
\end{tabular}

but not the role of crushing. Combined with the calculation ability of the computer, $0.05 \mathrm{~s}$ after initiation is the most appropriate time for the end of the numerical calculation.

\subsection{Analysis of Numerical Experiment Results}

2.4.1. Numerical Experiment Results. This section only shows the results of the numerical experiments, and all the figures mentioned are discussed later in Section 2.4.2. Figures 2(a)-2(i) are the $X$-direction velocity cloud diagram of bench blasting at $0.05 \mathrm{~s}$ under the 9 schemes, while Figure $2(\mathrm{j})$ is the statistics of the maximum horizontal velocity in the cloud diagram under each scheme at $0.05 \mathrm{~s}$ after blasting. These figures are discussed later in Section 2.4 .2 of the paper.

Table 5 shows the status of the crushing situation for the bench rock under each scheme. The boulder yield was calculated by dividing the total volume of the boulder by the total volume of the crushing block. Figure 3 shows the boulder yield statistics under each scheme.

Figure 4 shows the back-pulling situation under each scheme, where Figures 4(a)-4(i) show the variation of point $D$ displacement versus time, and Figure $4(j)$ is the statistics of the maximum displacement of point $D$ under each scheme.

2.4.2. Analysis of Blasting Effect. The blasting effect evaluation method introduced in Section 1 was used to quantitatively evaluate the bench blasting effects from the 9 schemes. Table 6 gives a comprehensive ranking of the blasting effect. This shows that scheme 3 gave the best effect while scheme 8 gave the worst effect. Table 7 is the range analysis table reflecting the degree of influence on the results. The range indicates the influence degree of some factors on the results, and the larger the range is, the greater the influence degree of the factors on the results is. From the range analysis results in Table 7 , it was seen that the thickness of the master weak interlayer had the greatest influence on the blasting effect followed by the wave impedance. The height of the weak interlayer from the chassis had the least influence. Figure 5 shows the effect of factors on the trend of results. The vertical axis is the ranking of the blasting effect, and the horizontal axis distributes the three levels of the master weak interlayer thickness, height, and wave impedance. This showed in turn that the blasting effect became worse with the increase of the thickness and the decrease of the wave impedance of the weak interlayer. The distance between the weak interlayer and the chassis had only a minor influence on the blasting effect and thus showed a trivial influence trend.

The above analysis showed that the two main factors that affect the blasting effect of weak interlayer were the thickness and wave impedance of the weak interlayer. It showed that in bench blasting of rock masses with multiple layers of different thicknesses and different wave impedances, it was feasible to combine the wave impedance and thickness of each weak interlayer in a certain way to determine the master weak interlayer.

\section{Analysis of Mechanistic Influences}

To explore the influence mechanism of the weak interlayer on the blasting effect, the velocity monitoring curves of points $A, B$, and $C$ during the blasting process were analyzed. The mechanistic influences from the weak interlayer on the energy distribution characteristics of explosives were clarified. Adopting the principle of the minimum resistance line, the reason for the change in the direction of action of weak interlayer on explosives was summarized. On this basis, a charging method to improve the bench blasting effect of weak interlayer was proposed.

\subsection{The Effect of Weak Interlayer on the Energy Distribution of} Explosives. Figures 6(a)-6(i) are the velocity monitoring curves for point $A$ at the top of the bench, point $B$ of the weak interlayer, and point $C$ at the bottom of the bench, respectively. Figure 6(j) shows the average velocity difference calculated based on the velocity monitoring data at the 3 points. As can be seen from this figure, no matter which scheme of the blasting process was considered, the velocity of point $B$ was much greater than the velocity at points $A$ and $C$. The distribution of the velocity field can represent the distribution of energy, indicating that when considering the blasting of a bench containing a weak interlayer, too much explosive energy was concentrated in and leaked through the weak interlayer. 


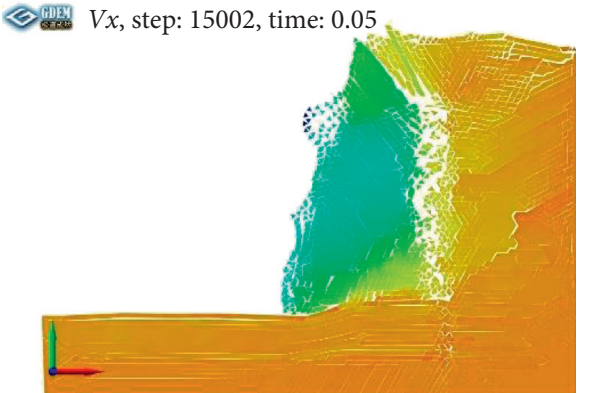
\begin{tabular}{|l}
2.86 \\
-0.09 \\
-3.03 \\
-5.98 \\
-8.92 \\
-11.87 \\
-14.81 \\
-17.76 \\
-20.70 \\
-23.65 \\
-26.60
\end{tabular}

(a)

(6) $V x$, step: 15002, time: 0.05

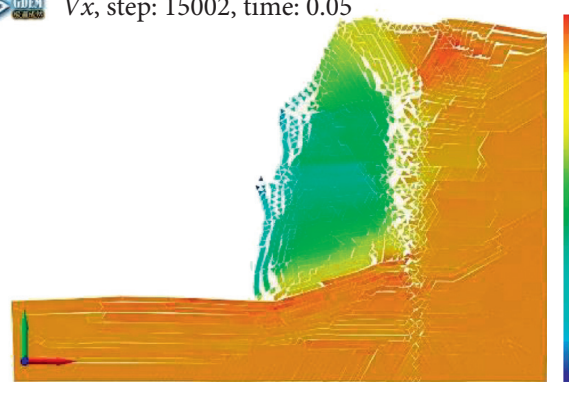

2.99
0.06
-2.88
-5.81
-8.75
-11.69
-14.62
-17.56
-20.50
-23.43
-26.37

(c)

(15) $V x$, step: 15002, time: 0.05

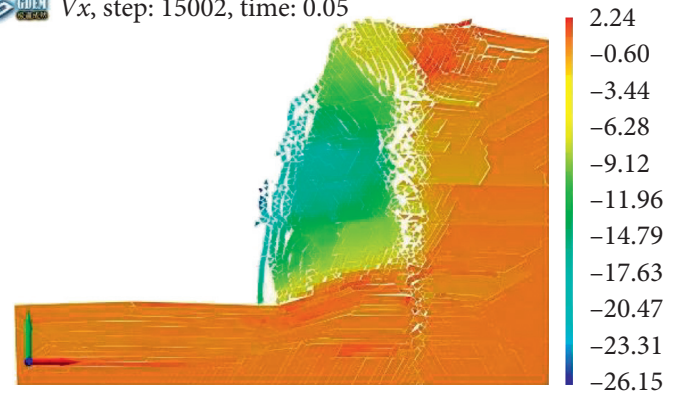

(e)

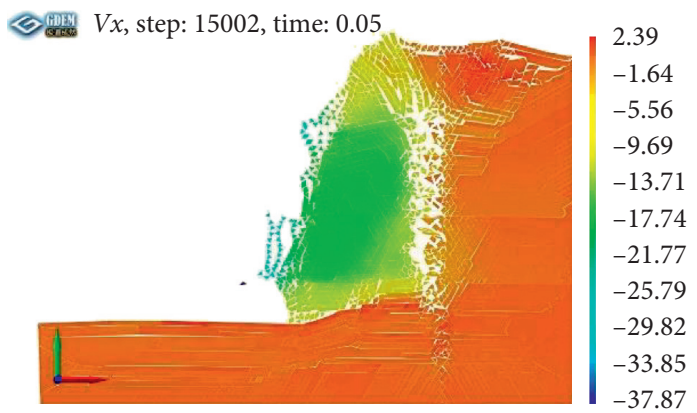

(g)

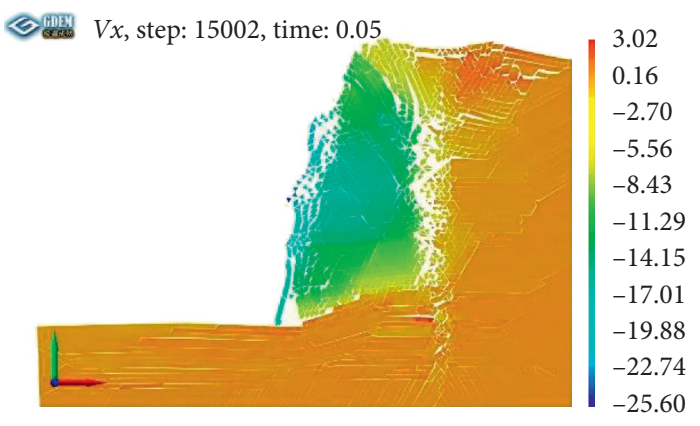

(b)

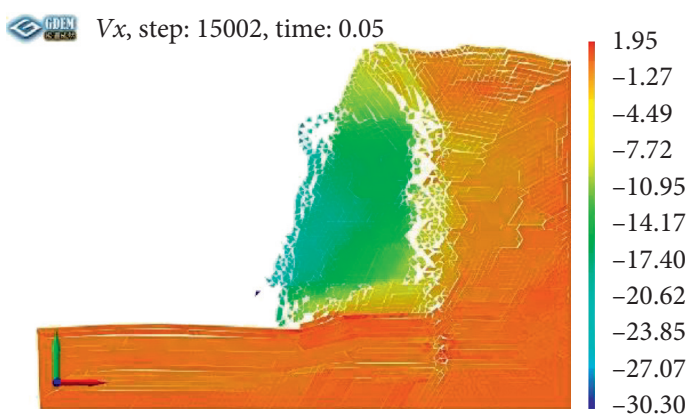

(d)

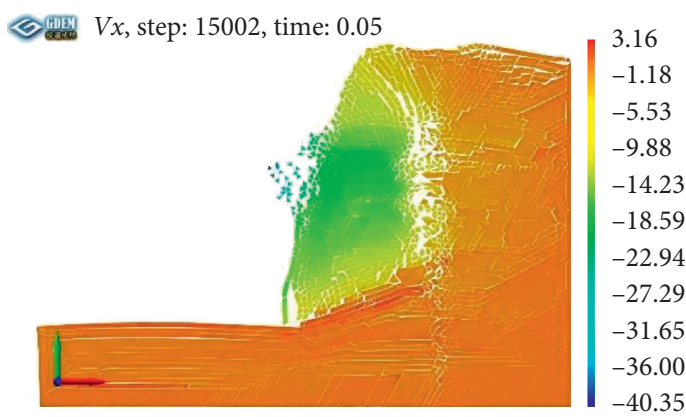

(f)

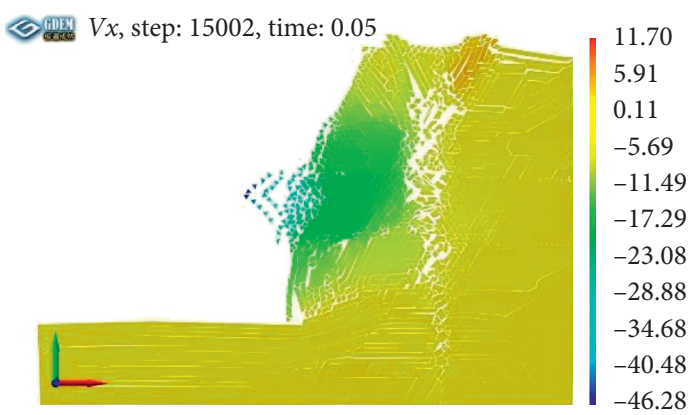

(h)

Figure 2: Continued. 


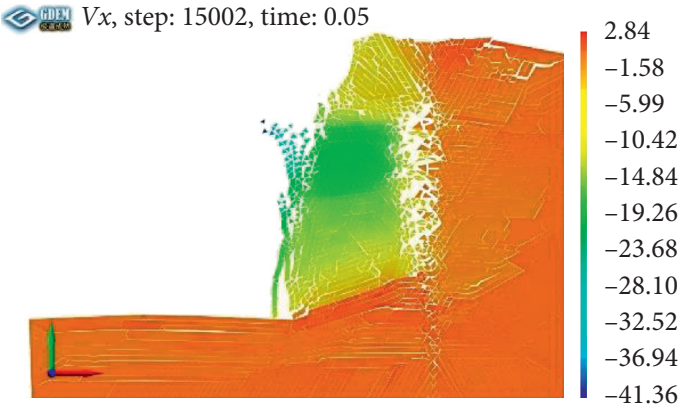

(i)

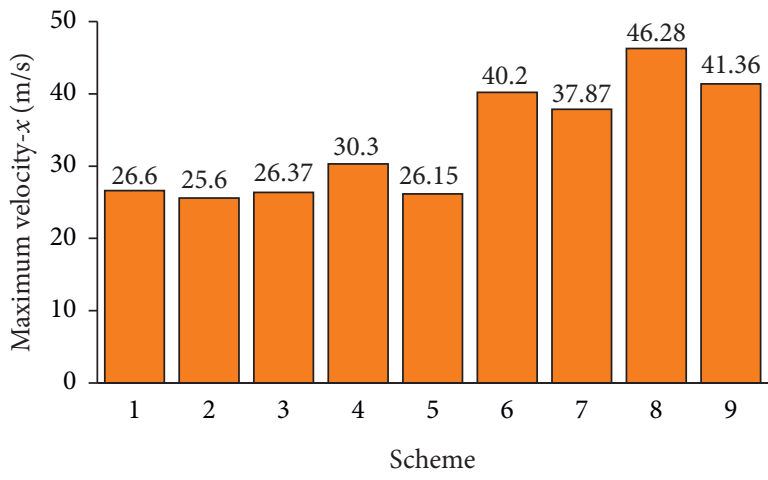

(j)

FIgURE 2: (a)-(i) Velocity distribution diagram in $x$-direction at $0.05 \mathrm{~s}$ of blasting under 9 schemes (units in (a)-(i) are all $\mathrm{m} / \mathrm{s}$ ). (j) Maximum velocity- $x$ statistics. (a) Scheme 1. (b) Scheme 2. (c) Scheme 3. (d) Scheme 4. (e) Scheme 5. (f) Scheme 6. (g) Scheme 7. (h) Scheme 8. (i) Scheme 9. (j) Maximum velocity- $x$ statistics.

TABLE 5: Bench rock crushing situation.

\begin{tabular}{|c|c|c|c|c|c|c|c|c|c|}
\hline Scheme & 1 & 2 & 3 & 4 & 5 & 6 & 7 & 8 & 9 \\
\hline Number of blocks & 938 & 877 & 1030 & 1114 & 1045 & 1077 & 1168 & 1149 & 1130 \\
\hline Total volume of blocks $\left(\mathrm{m}^{3}\right)$ & 38.30 & 38.60 & 38.15 & 38.68 & 38.61 & 38.89 & 38.51 & 38.83 & 38.96 \\
\hline Number of boulders & 2 & 3 & 1 & 3 & 3 & 3 & 4 & 4 & 3 \\
\hline Total volume of boulders $\left(\mathrm{m}^{3}\right)$ & 1.14 & 0.85 & 0.56 & 1.42 & 1.49 & 1.41 & 1.59 & 2.87 & 1.62 \\
\hline Boulder yield (\%) & 2.99 & 2.19 & 1.48 & 3.67 & 3.86 & 3.62 & 4.12 & 7.39 & 4.16 \\
\hline
\end{tabular}

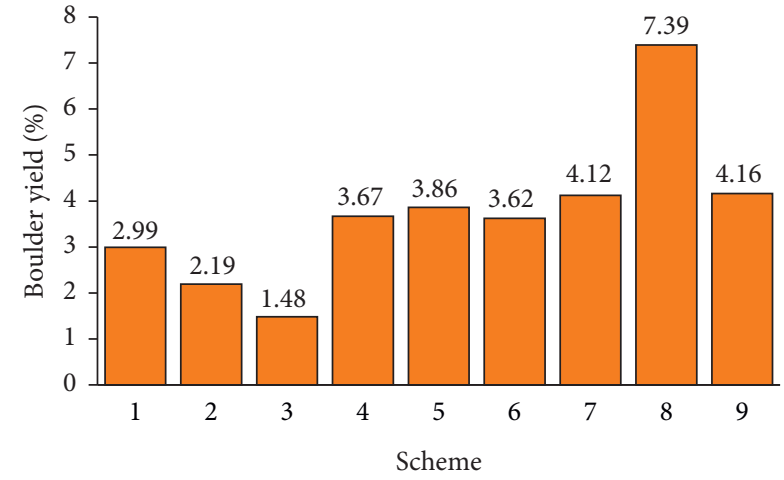

FIgURE 3: Statistics of boulder yield.

To further quantitatively analyze the degree of uneven distribution of explosive energy in the blasting process under the 9 schemes, the velocity monitoring curve under each scheme was subjected to mathematical cum statistical analysis. The specific process was as follows. (1) Find the average velocity of each of the three points under each scheme. (2) Calculate the difference between the average velocity of point $\mathrm{B}$ and the average velocity of points $A$ and $C$, expressed as $\Delta_{B A}$ and $\Delta_{B C}$, respectively. (3) Calculate $\Delta_{V}=\Delta_{B A}+\Delta_{B C}$ under each scheme. Figure 6(j) gives the histogram of $\Delta_{V}$ under each scheme, which shows that the thicker the weak interlayer and the smaller the wave impedance, the larger was the $\Delta_{V}$ of the scheme. It indicated that the smaller the interlayer wave impedance and the greater the thickness, the more explosive energy will be concentrated in the weak interlayer and leak through it.
To explore the relationship between the degree of uneven distribution of explosive energy in the blasting bench rock body and the blasting effect, the $\Delta_{V}$ under each scheme was sorted from small to large and compared with the ranking of the blasting effect. The results are shown in Figure 7, which shows that, generally, the blasting effect becomes worse if $\Delta_{V}$ becomes larger. This showed that the thicker the weak interlayer and the smaller the wave impedance, the more uneven the explosive energy distribution in the bench, the greater the leakage at the weak interlayer, and thus the worse the blasting effect of the bench rock mass.

3.2. Principle of Minimum Resistance Line. The shortest distance from the center of the grain to the free surface is known as the minimum resistance line, along the direction in which the explosive energy will first propagate. However, when a weak interlayer was present, the explosive stress wave does not completely propagate in the direction of the minimum resistance line, which makes the final blasting effect deviate from the design requirements. Stress waves will reflect and transmit at the interface of different media. Since the wave impedance of the weak interlayer was small, it was equivalent to forming a weak free surface in the bench, which will affect the direction of the minimum resistance line in the bench. As shown in Figure 8, the minimum resistance line was the vertical distance from the center of the grain to the free slope surface (dotted line). When there was a weak free surface formed by the master weak interlayer, the minimum resistance line changed according to the weak free surface, resulting in a new minimum resistance line direction (double-dotted line). The specific direction was related 


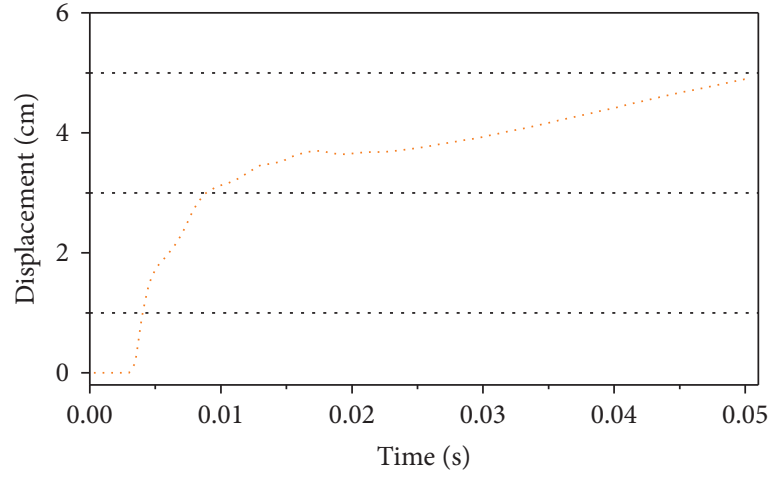

Scheme 1

(a)

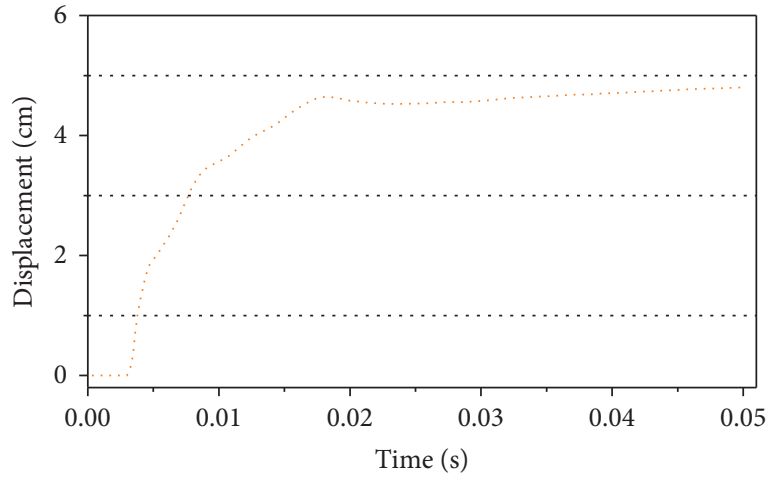

Scheme 3

(c)

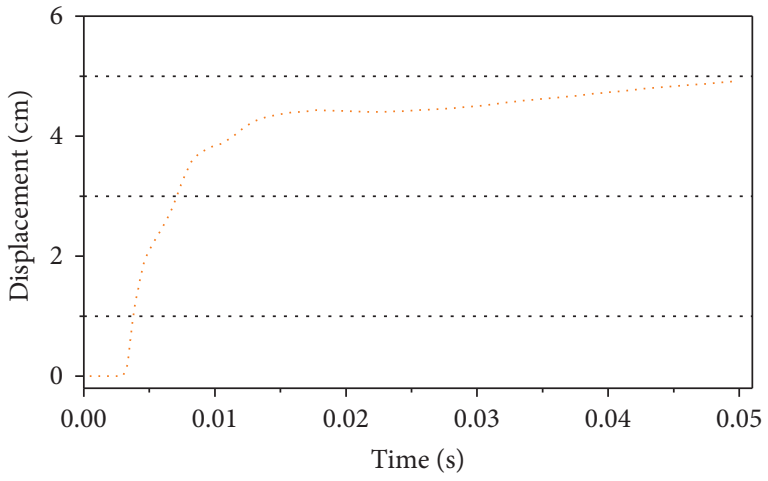

Scheme 5

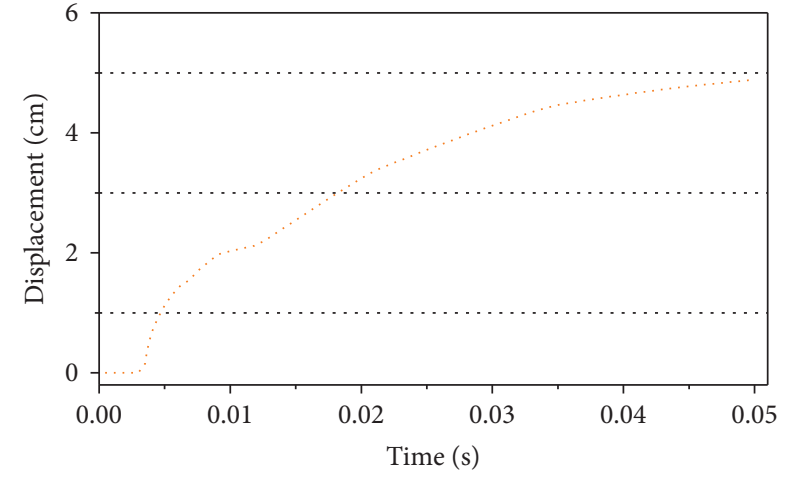

Scheme 2

(b)

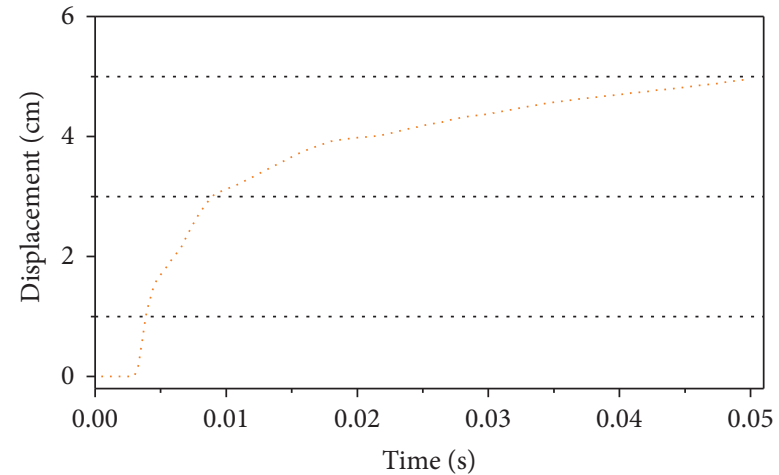

Scheme 4

(d)

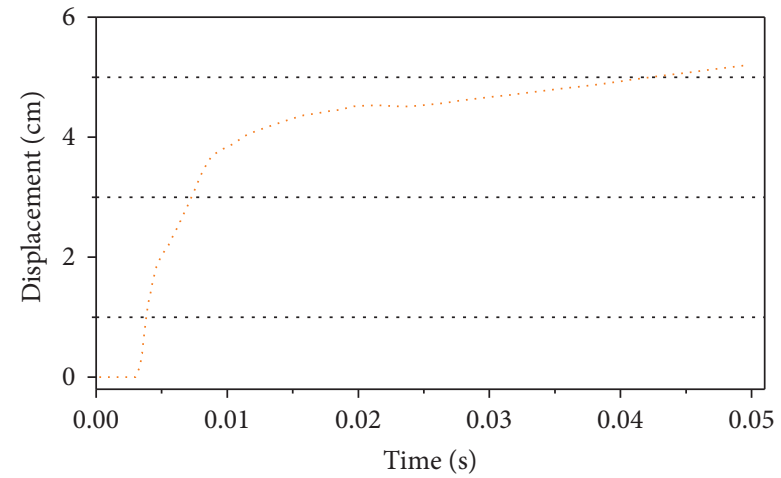

Scheme 6

(e)

(f)

Figure 4: Continued. 


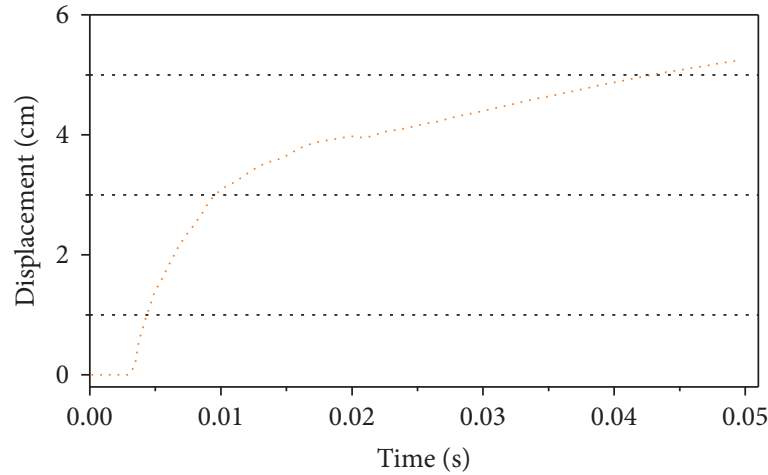

Scheme 7

(g)

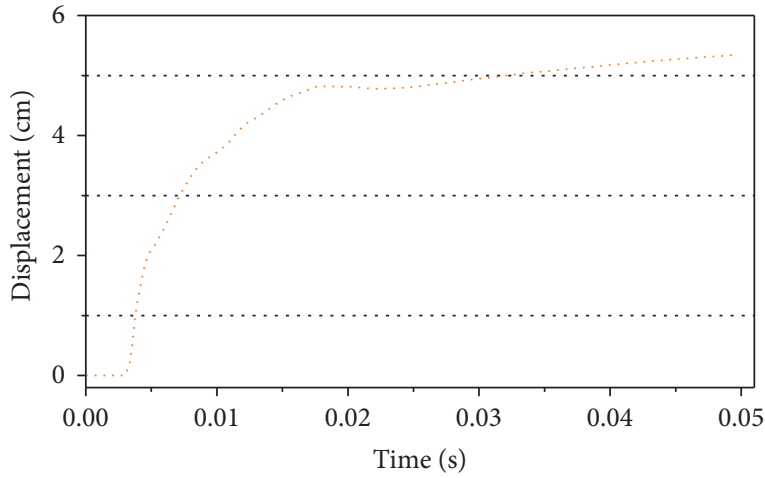

Scheme 9

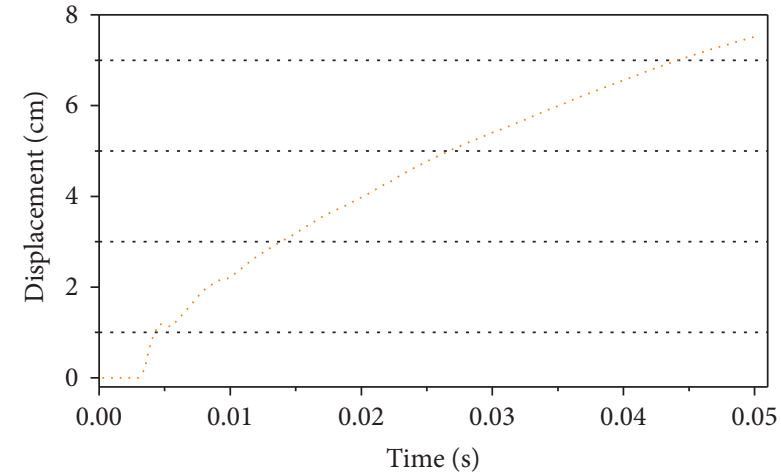

Scheme 8

(h)

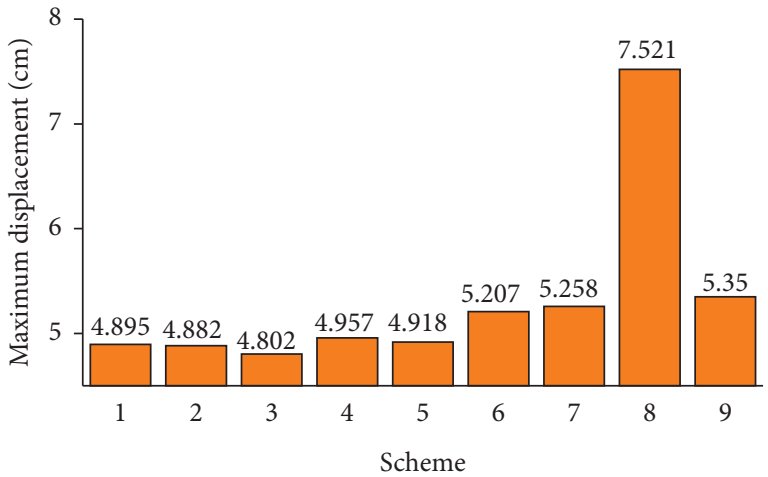

(j)

FIGURE 4: Bench back-pulling situation diagram. (a)-(i) Displacement monitoring curve under 9 schemes. (j) Statistics of the maximum displacement under 9 schemes. (a)Displacement monitoring curve of scheme 1. (b) Displacement monitoring curve of scheme 2.

(c)Displacement monitoring curve of scheme 3. (d) Displacement monitoring curve of scheme 4. (e)Displacement monitoring curve of scheme 5. (f) Displacement monitoring curve of scheme 6. (g)Displacement monitoring curve of scheme 7. (h) Displacement monitoring curve of scheme 8. (i)Displacement monitoring curve of scheme 9. (j) Statistics of the maximum displacement.

TABLE 6: Blasting effect calculation.

\begin{tabular}{|c|c|c|c|c|c|c|c|c|c|}
\hline Scheme & 1 & 2 & 3 & 4 & 5 & 6 & 7 & 8 & 9 \\
\hline Boulder yield (\%) & 2.91 & 2.83 & 2.19 & 3.67 & 3.86 & 3.62 & 3.91 & 7.39 & 4.16 \\
\hline Score & 7 & 8 & 9 & 5 & 4 & 6 & 3 & 1 & 2 \\
\hline 50 ms velocity $(\mathrm{m})$ & 26.6 & 25.6 & 26.37 & 30.3 & 26.15 & 40.2 & 37.87 & 46.28 & 41.36 \\
\hline Score & 6 & 9 & 7 & 5 & 8 & 3 & 4 & 1 & 2 \\
\hline Back edge displacement $(\mathrm{cm})$ & 4.895 & 4.882 & 4.802 & 4.957 & 4.918 & 5.207 & 5.258 & 7.521 & 5.35 \\
\hline Score & 7 & 8 & 9 & 5 & 6 & 4 & 3 & 1 & 2 \\
\hline Total score & 20 & 25 & 25 & 15 & 18 & 13 & 10 & 3 & 6 \\
\hline Comprehensive ranking & 2 & 1 & 1 & 4 & 3 & 5 & 6 & 8 & 7 \\
\hline
\end{tabular}

to the wave impedance, thickness, and position of the master weak interlayer, leading to the corresponding change of the transmission direction of the explosive energy.

\subsection{The Influence Mechanism of Interval Charging on the Effect} of Blasting. According to the principle of changing the minimum resistance line of the master weak interlayer of the rock mass containing the weak interlayer, the center of the grain should be as far away as possible from the weak interlayer to reduce the influence of the master weak interlayer on the blasting effect. As shown in Figure 8, comparing continuous charging and interval charging, it was noted that the distance between the center position of the grain and the weak interlayer had been significantly increased regardless of it being either the upper half or the lower half of the interval charging. This reduces the probability of explosive energy leaking along the direction of the master weak interlayer and 
TABLE 7: Orthogonal experiment results.

\begin{tabular}{lcccc}
\hline Factor & Thickness & Height & Wave impedance & Experiment result \\
\hline Scheme 1 & 1 & 1 & 1 & 2 \\
Scheme 2 & 1 & 2 & 2 & 1 \\
Scheme 3 & 1 & 3 & 2 & 4 \\
Scheme 4 & 2 & 1 & 3 & 3 \\
Scheme 5 & 2 & 2 & 1 & 5 \\
Scheme 6 & 2 & 3 & 3 & 6 \\
Scheme 7 & 3 & 1 & 1 & 7 \\
Scheme 8 & 3 & 2 & 2 & \\
Scheme 9 & 3 & 3 & 5 & \\
Mean 1 & 1.333 & 4 & 4 & \\
Mean 2 & 4 & 4 & 3.333 & \\
Mean 3 & 7 & 4.333 & 1.667 & \\
Range & 5.667 & 0.333 & \multicolumn{2}{c}{} \\
\hline
\end{tabular}
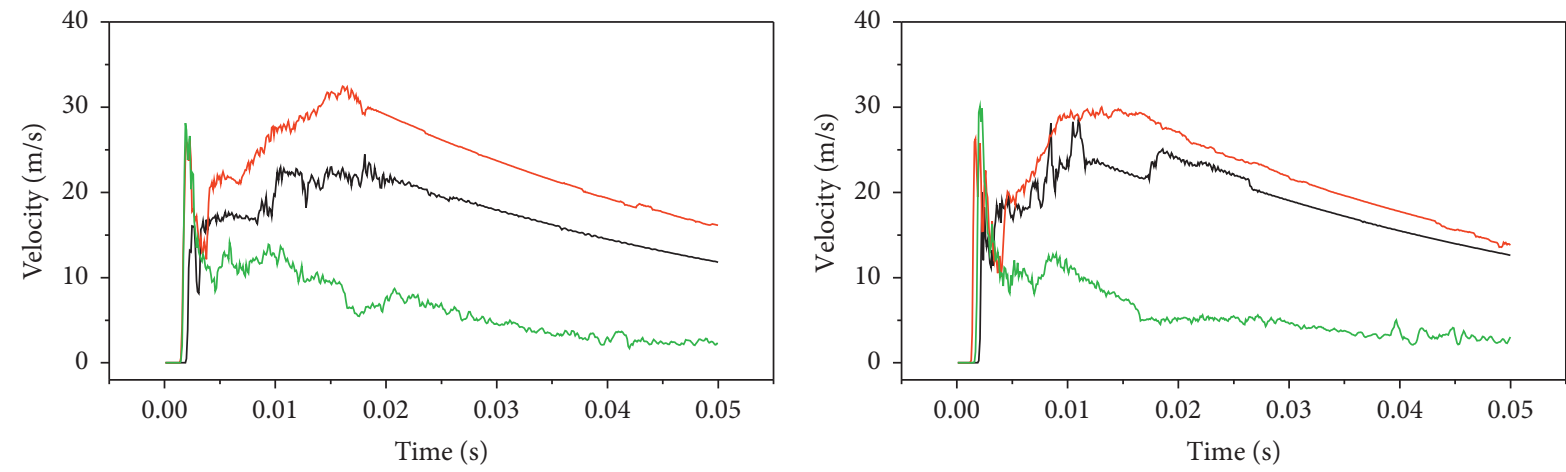

$$
\begin{array}{r}
-A \\
-B \\
-C
\end{array}
$$

(a)

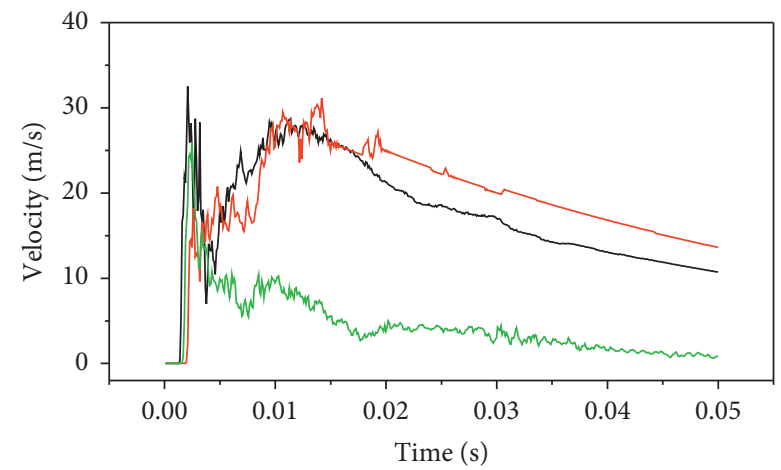
- A
$-C$
$A$
$-B$
$C$

- A

$-\quad$ C

(b)

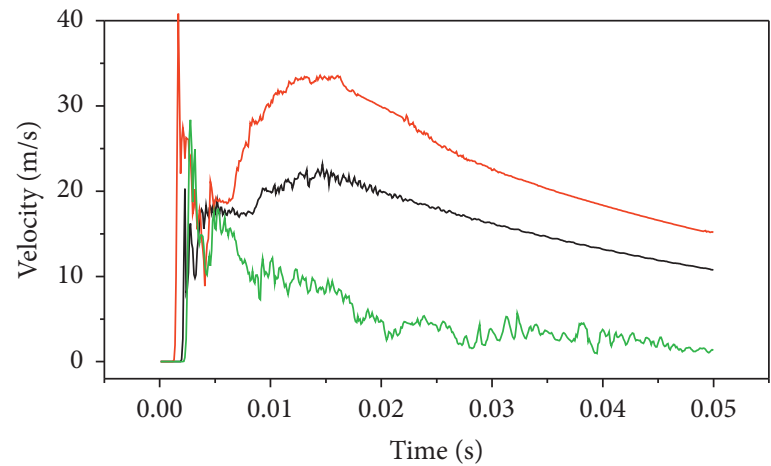

(c)

(d)

Figure 6: Continued. 

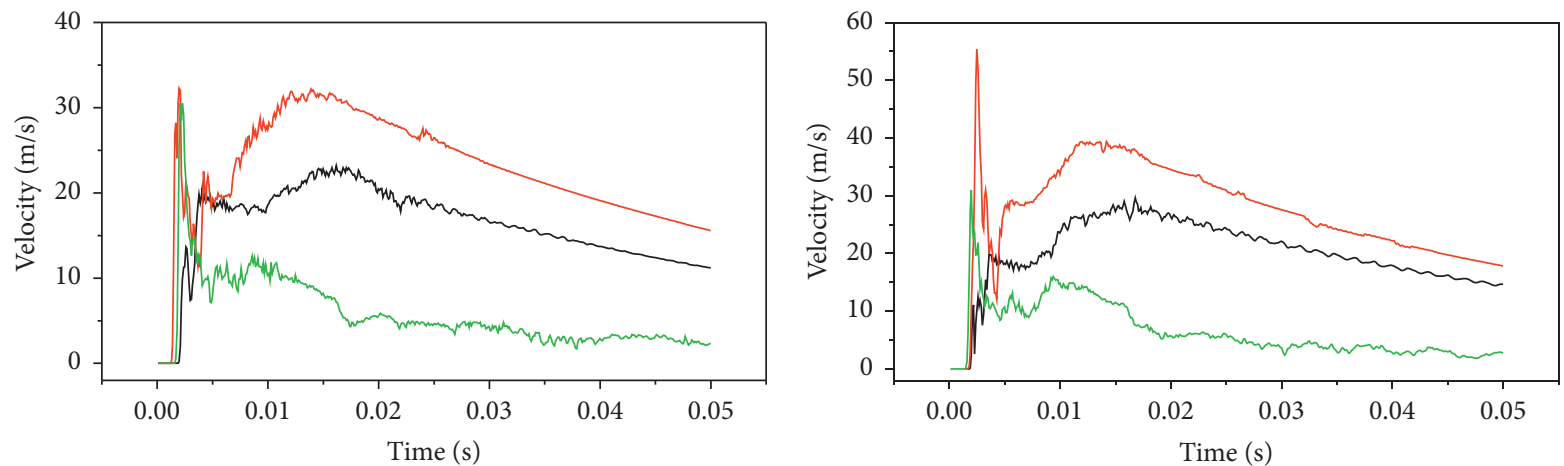

$$
\begin{array}{r}
-A \\
-B \\
-\quad C
\end{array}
$$

(e)

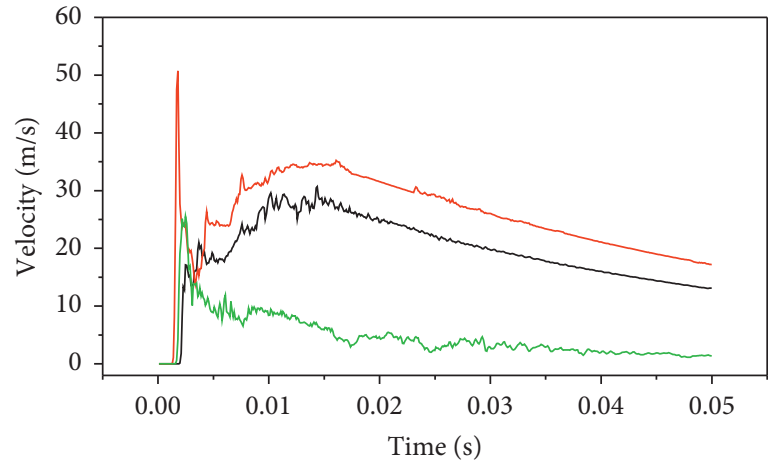

$-A$
$-B$
$-\quad C$

(g)

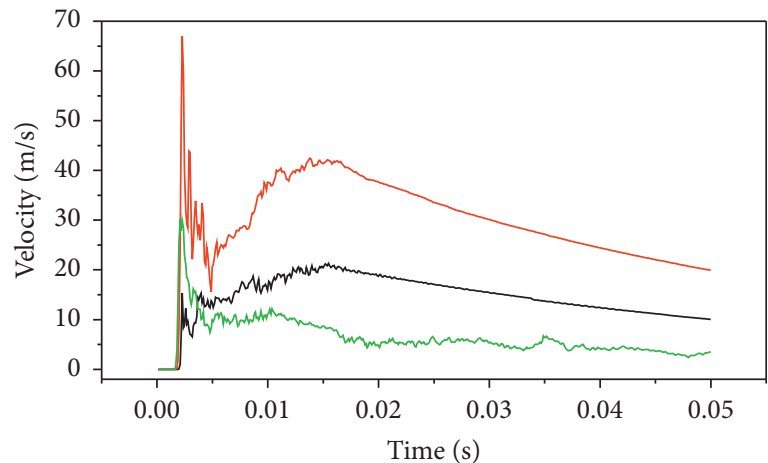

$-A$
$-B$
$-C$
- A

$-B$

$-C$

(f)

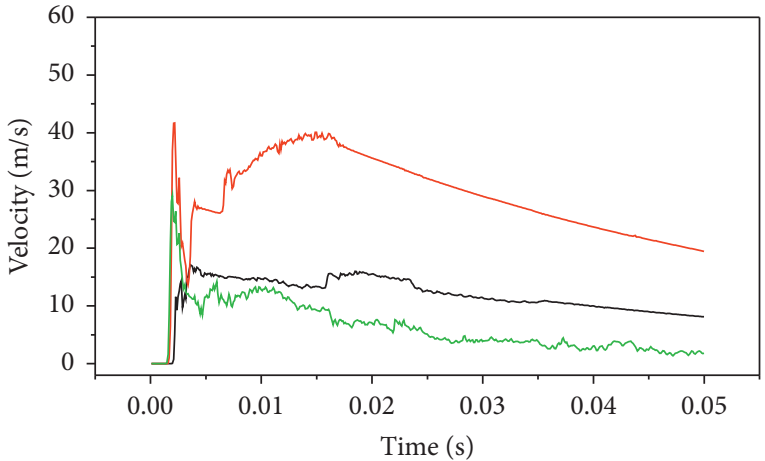

- A

$-B$

- C

(h)

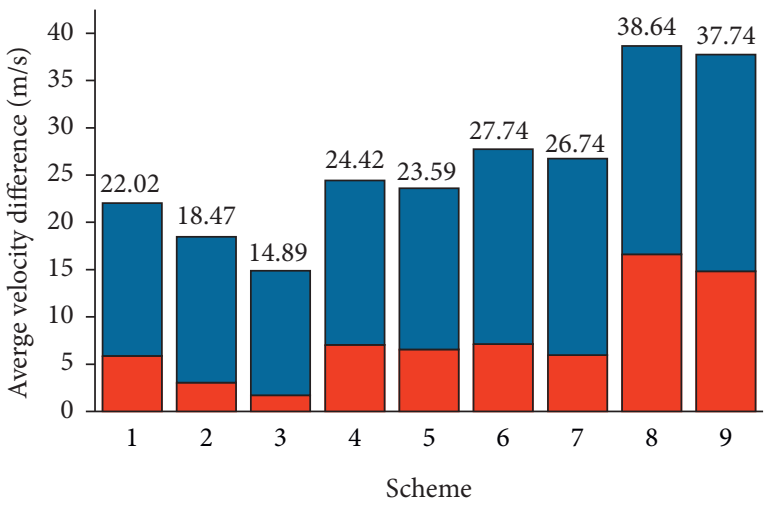

$\square \Delta_{B A}$

$\square \Delta_{B C}$

(i)

(j)

FIGURE 6: (a-i) Velocity monitoring curve under 9 schemes. (j) Statistics of average velocity differences under 9 schemes. Velocity monitoring curves of (a) scheme 1; (b) scheme 2; (c) scheme 3; (d) scheme 4; (e) scheme 5; (f) scheme 6; (g) scheme 7; (h) scheme 8; and (i) scheme 9. (j) Statistics of average velocity differences. 


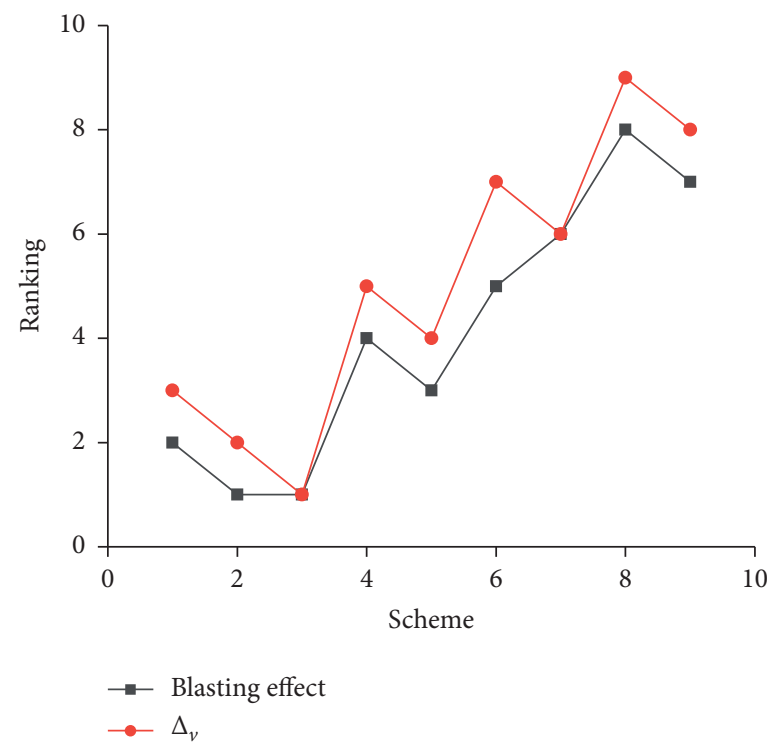

FIGURE 7: $\Delta_{\mathrm{V}}$ ranking and blasting effect ranking.

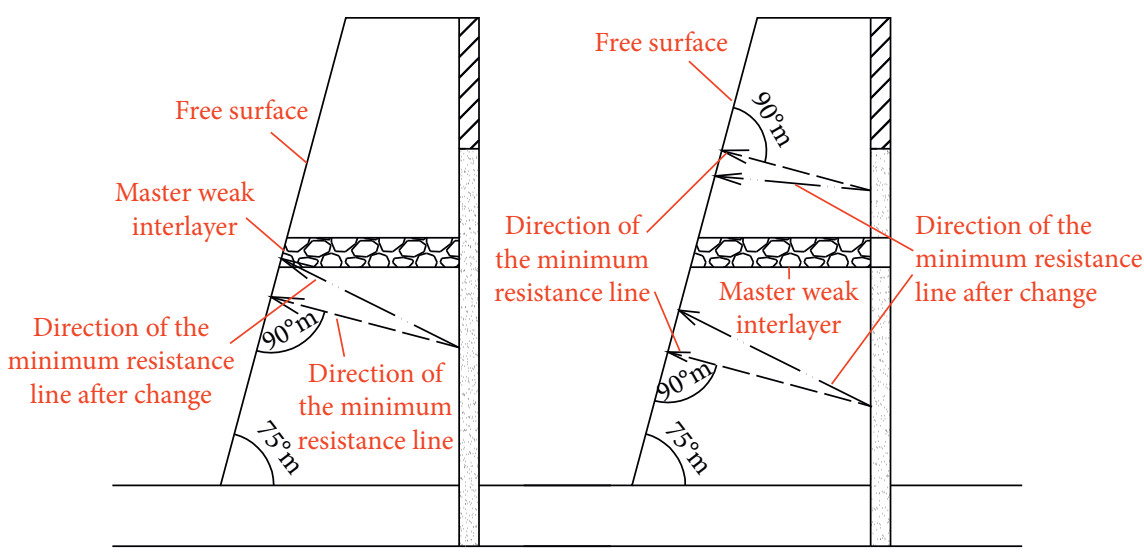

Figure 8: Principle of minimum resistance line.

thus reduced the adverse effect of the master weak interlayer on the blasting effect.

Therefore, interval charging was the key technology to solve interbedded stratum blasting. However, in the design process of the interval charging structure, the location of the master weak interlayer needed to be accurately determined to achieve good blasting effects. However, various combinations of the thickness, inclination, and mechanical parameters of each rock layer existed in the actual bench. Also, the overall and local engineering geological properties within the bench were constantly changing. As a result, the conditions that affect the energy distribution of explosives were also changing, which caused a certain degree of difficulty in quickly and accurately determining the location of the master weak interlayer.

\section{Construction of Evaluation Method for Master Weak Interlayer}

According to the thrust of this research, the thickness of the weak interlayer and wave impedance were the two main factors that affect the effect of bench blasting. To find out the influence of the combination of these two factors on the bench blasting effect, it was found that ranking the ratio of the wave impedance to the thickness of the weak interlayer $Z_{i}=R_{i} / D_{i}$ of the 9 schemes from large to small generally agreed with the comprehensive ranking of the blasting effect. Therefore, this indicated that it was theoretically feasible to determine the master weak interlayer by comparing the magnitude of $Z_{i}$. Table 8 is the calculation table of the $R_{i} / D_{i}$ ratio, and Figure 9 is the ranking of the ratio and the effect.

The evaluation method for determining the master weak interlayer was as follows. First, calculate the wave impedance $R_{i}=\rho_{i} * C_{i}$ of each layer separately, and find the largest wave impedance $R_{\max }$. Second, except for the rock layer with the largest wave impedance, divide the wave impedance of each rock layer by its thickness to get the ratio $Z_{\mathrm{i}}=R_{i} / D_{i}$. Third, sort $Z_{i}$ from small to large, with the first layer as the master and the second as the secondary master weak interlayer.

To obtain a satisfactory blasting effect when performing weak interlayer evaluation in actual blasting projects, one should combine the blasting experience and the actual 
TABLE 8: Calculation of $R_{i} / D_{i}$ ratio.

\begin{tabular}{lccccccccc}
\hline Scheme & 1 & 2 & 3 & 4 & 5 & 6 & 7 & 8 & 9 \\
\hline$R_{i} / D_{i}$ & 3.78 & 7.74 & 10.48 & 2.52 & 3.49 & 2.25 & 2.10 & 0.75 & 1.55 \\
$\begin{array}{l}\text { Ratio } \\
\text { ranking }\end{array}$ & 3 & 2 & 1 & 5 & 4 & 6 & 7 & 9 & 8 \\
$\begin{array}{l}\text { Effect } \\
\text { ranking }\end{array}$ & 2 & 1 & 1 & 4 & 3 & 5 & 6 & 8 & 7 \\
\hline
\end{tabular}

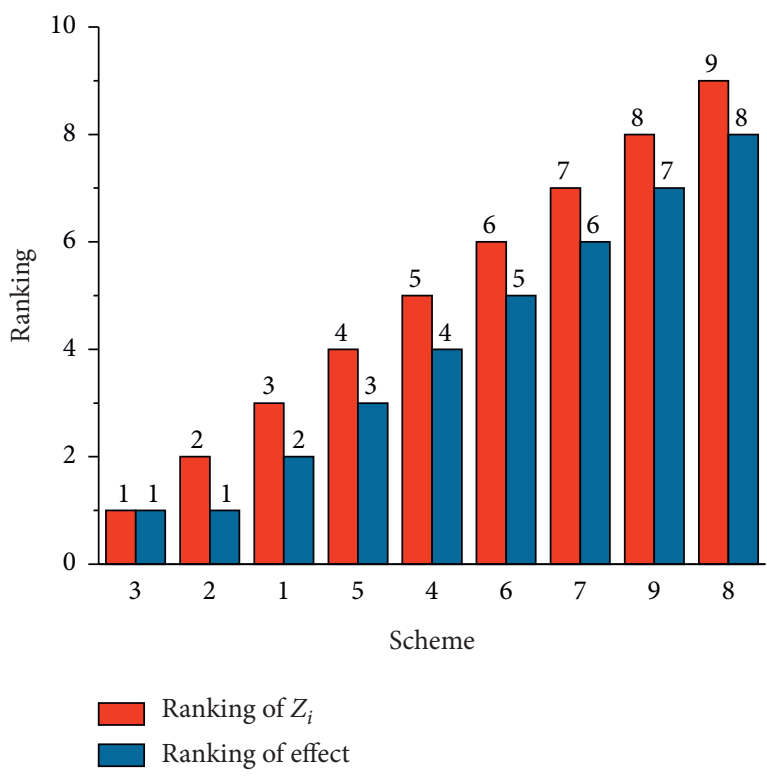

FIGURE 9: Ratio ranking and effect ranking.

situation on the site to choose interval charging only in the master weak interlayer or choose to perform interval charging on both the master weak interlayer and the secondary master weak interlayer.

\section{Validation of the Master Weak Interlayer Evaluation Method}

5.1. Evaluation Process of the Master Weak Interlayer. To validate the feasibility of the abovementioned evaluation method in the bench blasting of complex interbedded strata, a field study was conducted in an open-pit coal mine with typical soft and hard interbedded strata distribution. A control group was set up for comparison. The distribution of the rock formations of the blasting bench is shown in Figure 10.

The stratigraphy of the rock mass in the bench was comprised of 5 rock strata. All strata were in parallel contact. The rock formation was inclined to the free surface of the bench at an inclination angle of $5^{\circ}$, and the strike was the same as the extension direction of the free surface. On-site measurement, sampling, and indoor testing were carried out to determine the thickness, density, and longitudinal wave velocity of each layer which were thus obtained. The wave impedance value of each layer was obtained by calculation (see the $R_{i}$ wave impedance column in Table 9 for details). Due to the small inclination angle of the rock layers, the distance between the top and bottom surfaces of each rock

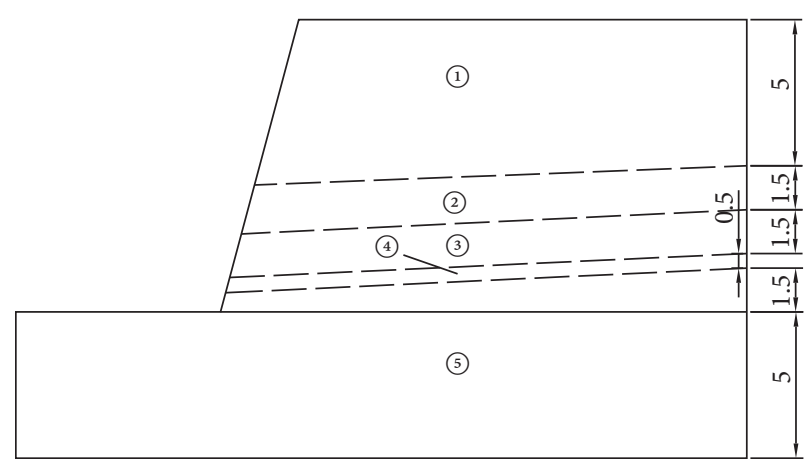

FIGURE 10: Schematic diagram of the distribution of rock layers (unit: $\mathrm{m}$ ).

layer in the plumb direction was approximately equal to the thickness of each rock stratum. For the convenience of calculation, this paper used the vertical distance between the top and bottom of the rock stratum to directly represent the thickness of the rock stratum. Since the rock layers had a certain inclination, the thickness of the (1) rock layer and the (5) rock layer varied with the location, and the specific thickness was therefore calculated according to the position of the blast hole.

The master weak interlayer evaluation was performed on the bench according to the master weak interlayer evaluation method introduced in Section 3. First, calculate the wave impedance of each rock mass in the bench, and find rock layer (1) with the maximum wave impedance. The calculated results are shown in the wave impedance column of Table 9. Second, except for the rock layer (1) with the maximum wave impedance, divide the wave impedance of the other layers by their thickness to get $Z_{i}$ of each layer. $Z_{i}$ of each layer is shown in the $Z_{i}$ column in Table 9. Third, sort $Z_{i}$ of each layer from small to large. The first-ranked rock layer (2) was the master weak interlayer, and the second-ranked rock layer (4) was the secondary master weak interlayer. The calculation process is shown in Table 9.

5.2. Numerical Experiment Validation. According to the analysis, it was determined that rock layer (2) was the master weak interlayer, and rock layer (4) was the secondary master weak interlayer. Three sets of experiments were designed in this numerical experiment to validate the rationality of the evaluation method. Experiment 1 used full-hole charge, experiment 2 used interval charging at the secondary master weak interlayer, and experiment 3 used interval charging at the master weak interlayer. Taking into account the computing power of the computer, only the two holes near the free surface in the blasting bench were selected for simulation in this numerical experiment. The bench geometry and charge structure are shown in Figure 11. The explosive material parameters, mechanical constitutive, and boundary conditions of this numerical experiment were the same as those in the numerical experiment of Section 1. The initiation point of blasting was set to be the center of the grain. To achieve a good blasting effect, millisecond 
TABLE 9: Evaluation calculation of the master weak interlayer.

\begin{tabular}{|c|c|c|c|c|c|c|c|}
\hline $\begin{array}{l}\text { Rock } \\
\text { stratum } \\
\text { number }\end{array}$ & $\begin{array}{l}\text { Longitudinal wave } \\
\text { velocity, } C_{i}(\mathrm{~m} / \mathrm{s})\end{array}$ & $\begin{array}{l}\text { Density, } \rho_{i} \\
\left(\mathrm{~kg} / \mathrm{m}^{3}\right)\end{array}$ & $\begin{array}{l}\text { Wave impedance, } \\
R_{i}\left(\mathrm{~kg} / \mathrm{m}^{2} \cdot \mathrm{s}\right)\end{array}$ & $\begin{array}{c}\text { Thickness, } D_{i} \\
(\mathrm{~m})\end{array}$ & $\begin{array}{c}\text { Wave impedance, } \\
Z_{i} \text { (thickness) }\end{array}$ & $\begin{array}{l}\text { Ration } \\
\text { ranking, } P_{i}\end{array}$ & $\begin{array}{c}\text { Master weak } \\
\text { interlayer } \\
\text { evaluation }\end{array}$ \\
\hline (1) & 2660 & 2480 & 6596800 & 5 & - & - & \multirow{5}{*}{$\begin{array}{l}\text { Master weak } \\
\text { interlayer } \\
\text { A secondary } \\
\text { master weak } \\
\text { interlayer }\end{array}$} \\
\hline (2) & 1322 & 1350 & 1784700 & 1.5 & 1189800 & 1 & \\
\hline (3) & 2668 & 2372 & 6328496 & 1.5 & 4218997 & 4 & \\
\hline (4) & 1360 & 1530 & 2080800 & 0.5 & 4161600 & 2 & \\
\hline (5) & 2663 & 2377 & 6329951 & 1.5 & 4219967 & 3 & \\
\hline
\end{tabular}

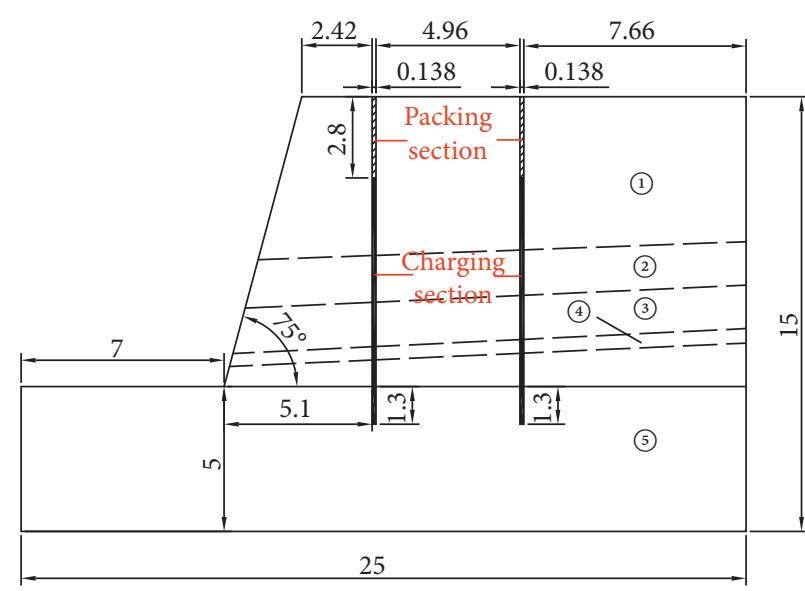

(a)

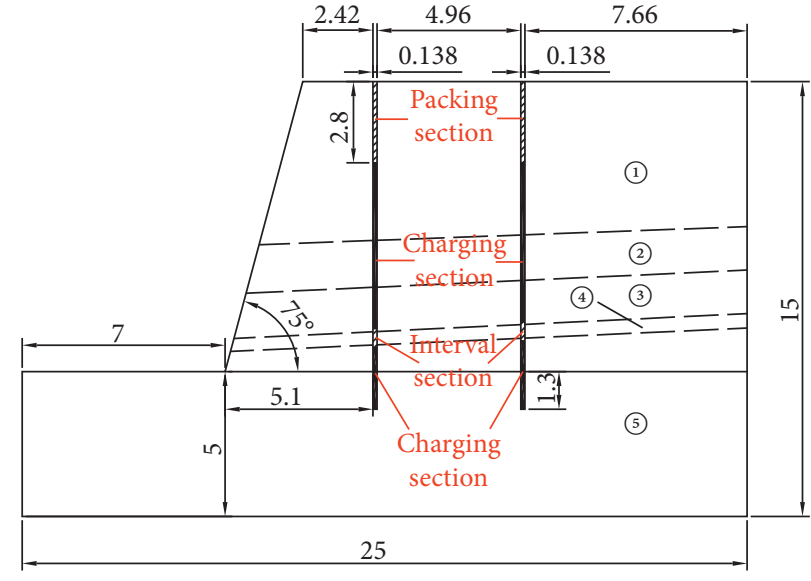

(b)

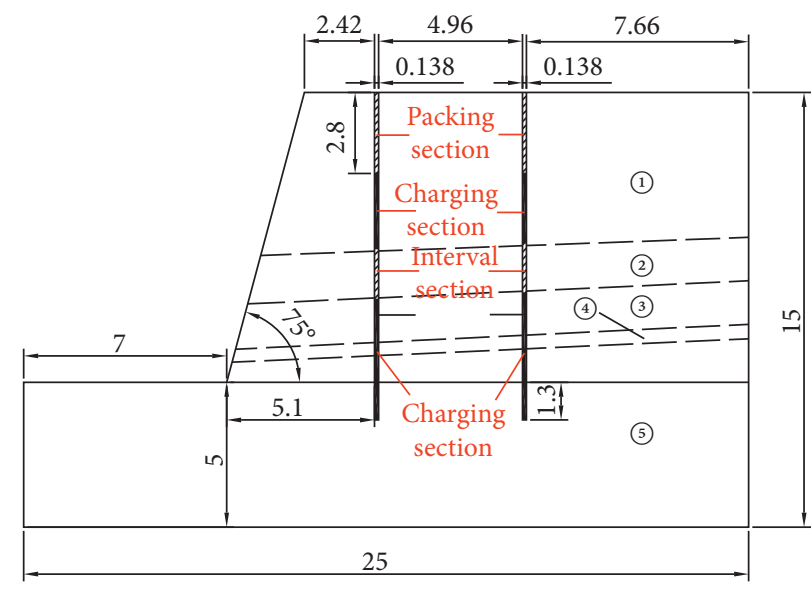

(c)

FIGURE 11: Charging structure (unit: m). (a) Full-hole charge; (b) interval charging at the secondary master weak interlayer; (c) interval charging at the master weak interlayer.

differential initiation was used between the two holes in all three sets of experiments with the initiation interval being set at $0.025 \mathrm{~s}$.

The results thus calculated are shown in Table 10 and Figures 12-14. Figure 12 shows the velocity cloud map in the $x$-direction at $0.1 \mathrm{~s}$ after blasting, and Table 10 shows the crushing situation in the bench rock mass. Figure 13 shows the boulder yield statistical graph, and Figure 14 shows the displacement monitoring graph at the back of the bench. The blasting effect evaluation method in this experiment was the same as the method proposed in Section 1.2. It is seen from Figure 12 that at $0.1 \mathrm{~s}$ after blasting, the maximum velocity of the bench rock mass of continuous charge was the largest. The maximum velocity of interval charging at the master weak interlayer was the smallest, and the maximum velocity of interval charging at the secondary master weak interlayer 
TABLE 10: Bench rock crushing situation.

\begin{tabular}{lccc}
\hline Experiment & 1 & 2 & 3 \\
\hline Number of blocks & 2877 & 3389 & 3722 \\
Total volume of blocks $\left(\mathrm{m}^{3}\right)$ & 94.28 & 97.32 & 100.27 \\
Number of boulders & 9 & 8 & 1 \\
Total volume of boulders $\left(\mathrm{m}^{3}\right)$ & 6.61 & 3.52 & 2.85 \\
Boulder yield $(\%)$ & 7.01 & 3.61 & 2.84 \\
\hline
\end{tabular}

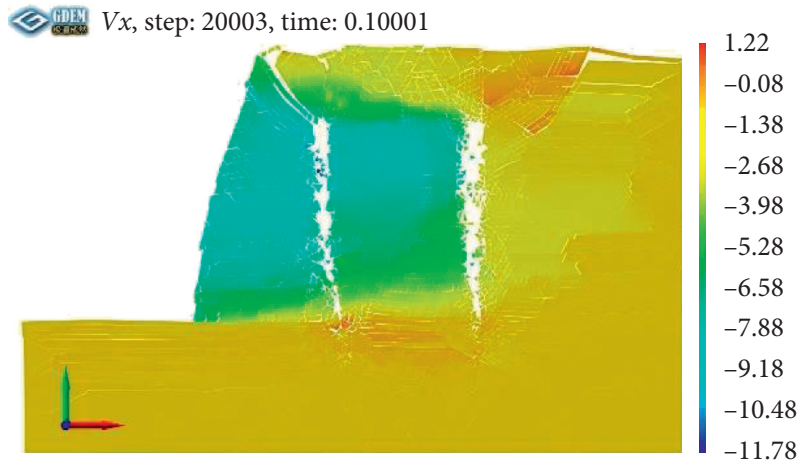

(a)

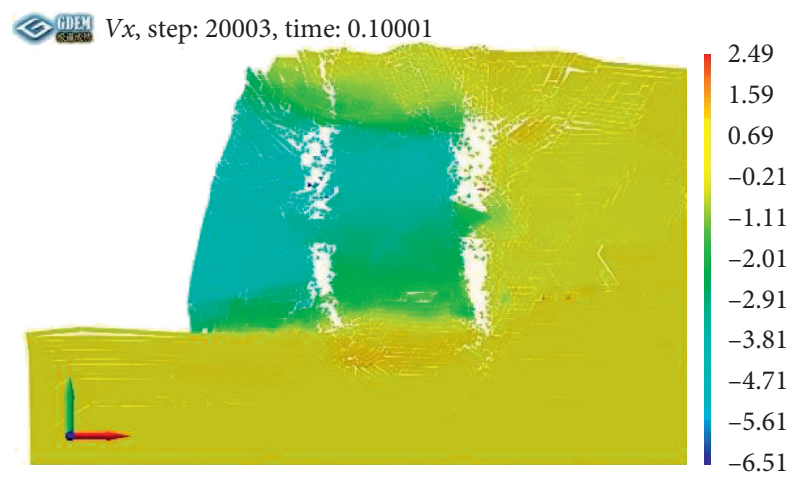

(c)

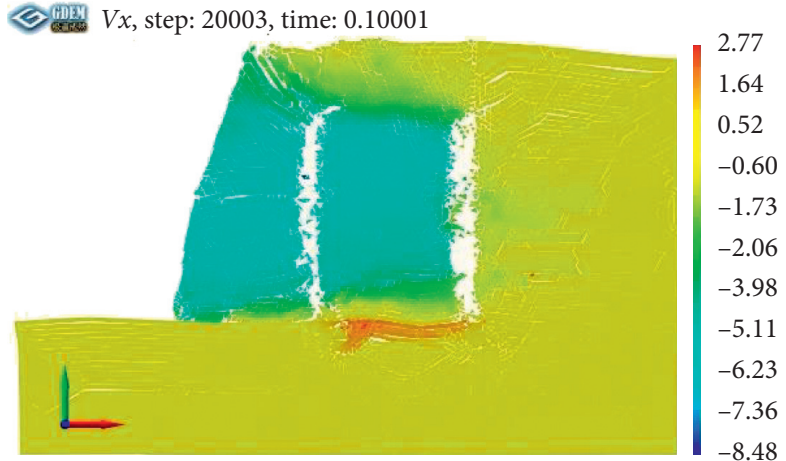

(b)

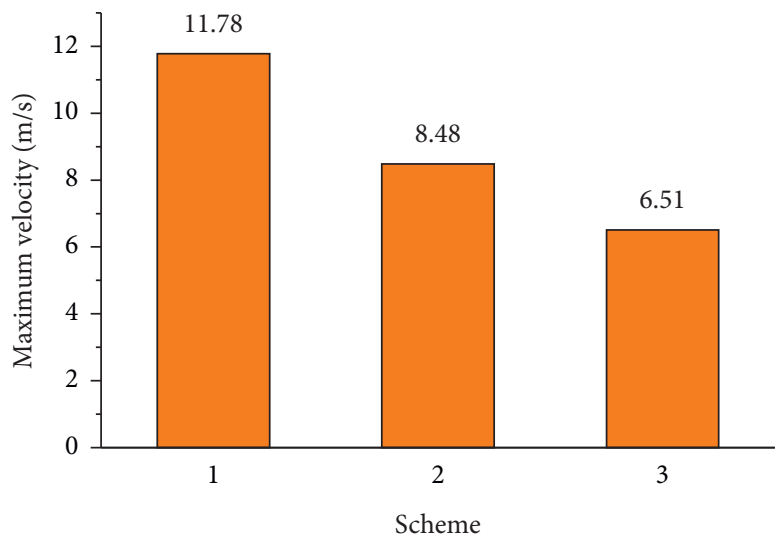

(d)

FIGURE 12: $(\mathrm{a}-\mathrm{c})$ The velocity distribution in the $x$-direction at $0.1 \mathrm{~s}$ after blasting. (a) Scheme 1. (b) Scheme 2. (c) Scheme 3. (d) Statistics of maximum velocity- $x$.

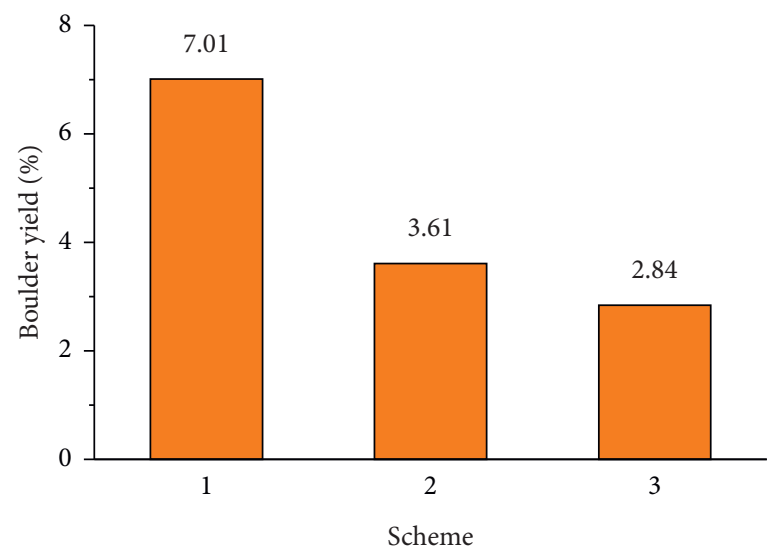

FIGURE 13: Boulder yield statistics. 


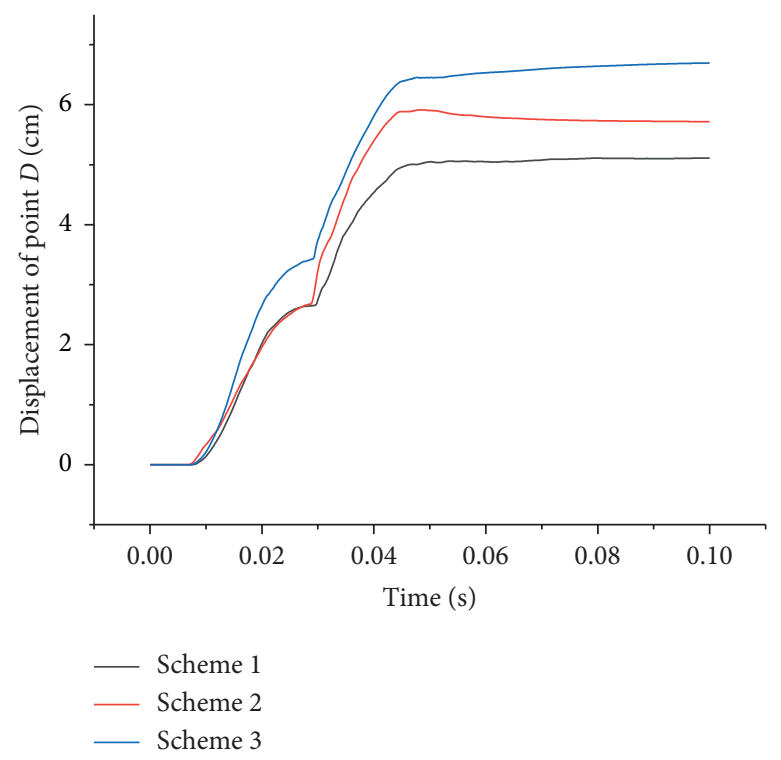

FIGURE 14: Displacement of the bench back.

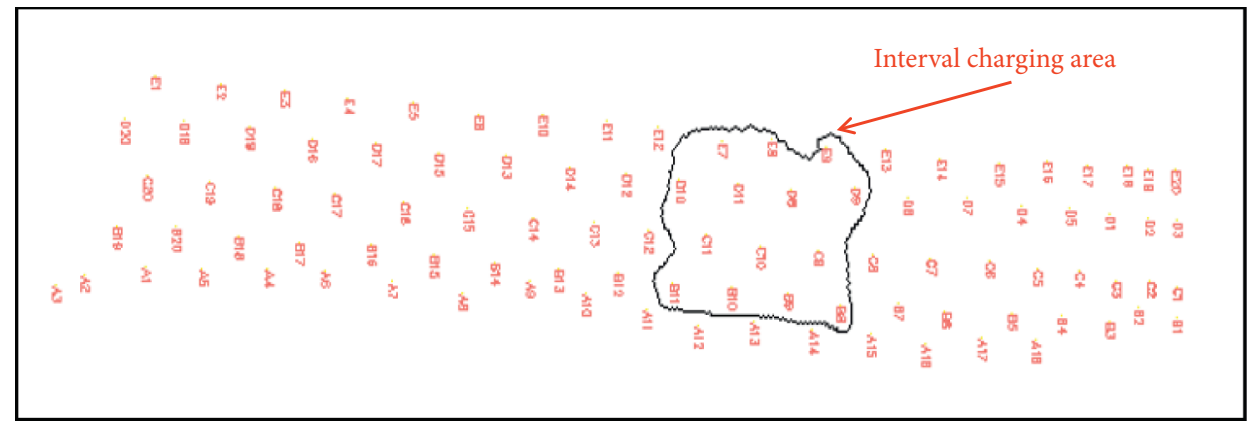

(a)

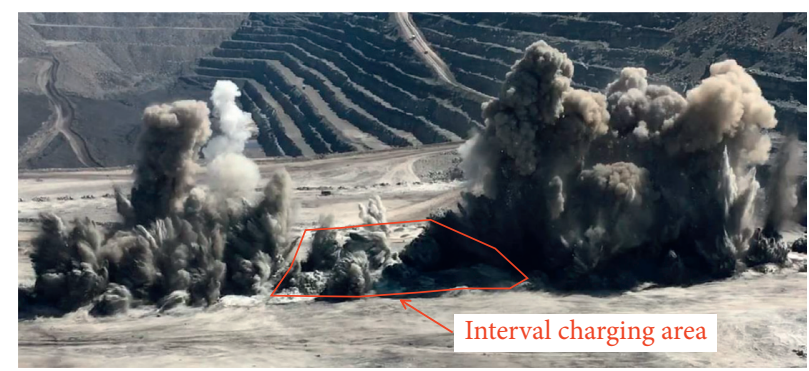

(b)

FIgURE 15: Comparison of punching in the blasting process. (a) Layout of blast holes in the explosion zone. (b) Blasting process.

was mediocre. Figures 13 and 14 show that the boulder yield of the crushing rock mass and the maximum displacement of the back edge of the bench also showed the same behavior as the maximum velocity. This indicated that the blasting effect of bench rock mass was the best when using interval charging in the master weak interlayer, followed by interval charging in the secondary master weak interlayer interval, and the blasting effect of continuous charging was the worst. Numerical experimental results showed that this master weak interlayer judgment method was feasible for guiding interval charging of rock masses with multilayer weak interlayer bench.

5.3. Field Test Validation. The above numerical experiments showed that it was feasible to use the master weak interlayer evaluation method proposed in Section 3 to identify the master weak interlayer. To further validate the feasibility of this method, this paper carried out a comparative test on the blasting site and designed two charging structures: 


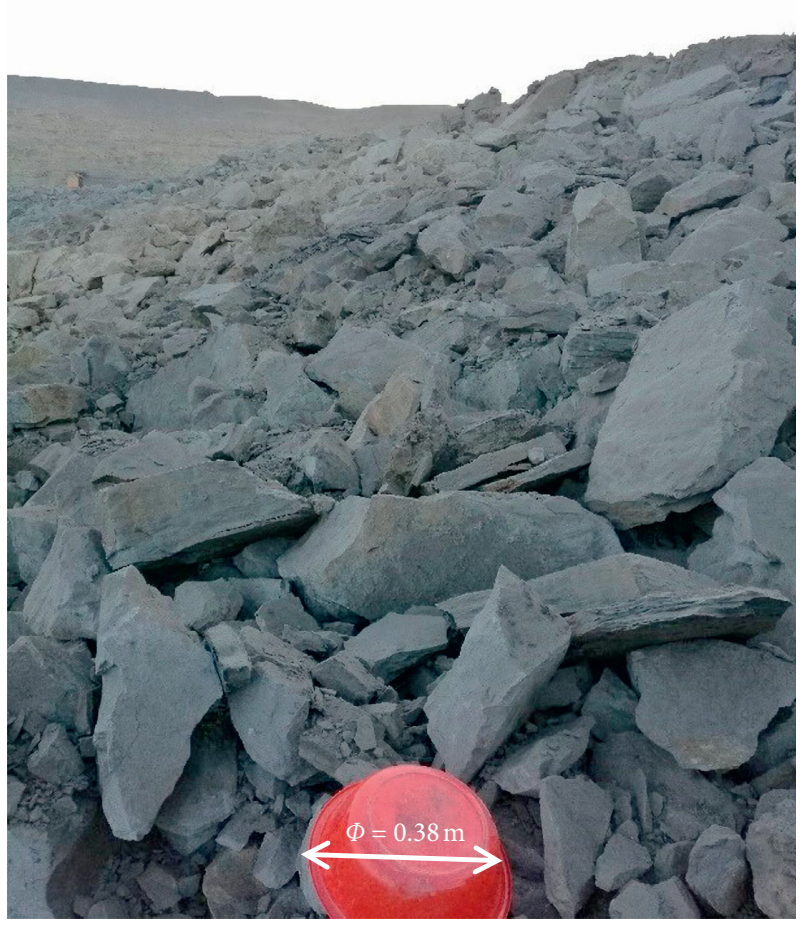

(a)

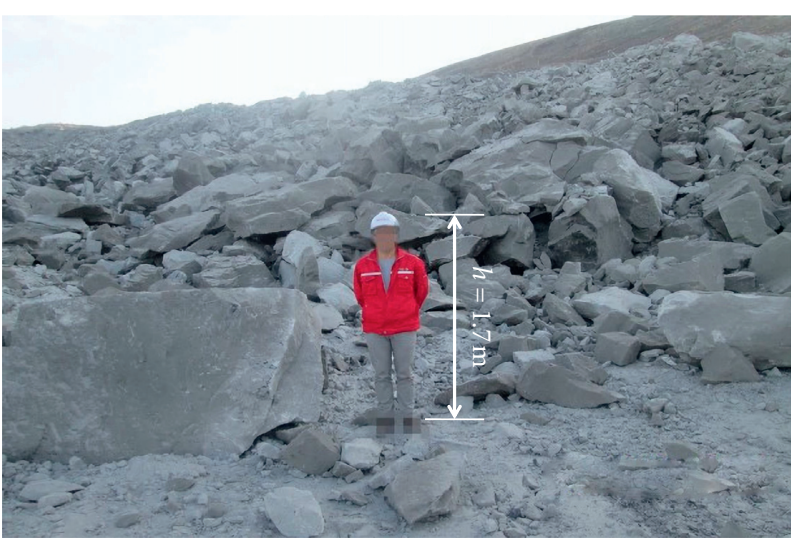

(b)

FIGURE 16: Comparative analysis of rock mass crushing. (a) Crushing result of rock mass in the test group. (b) Crushing result of rock mass in the control group.

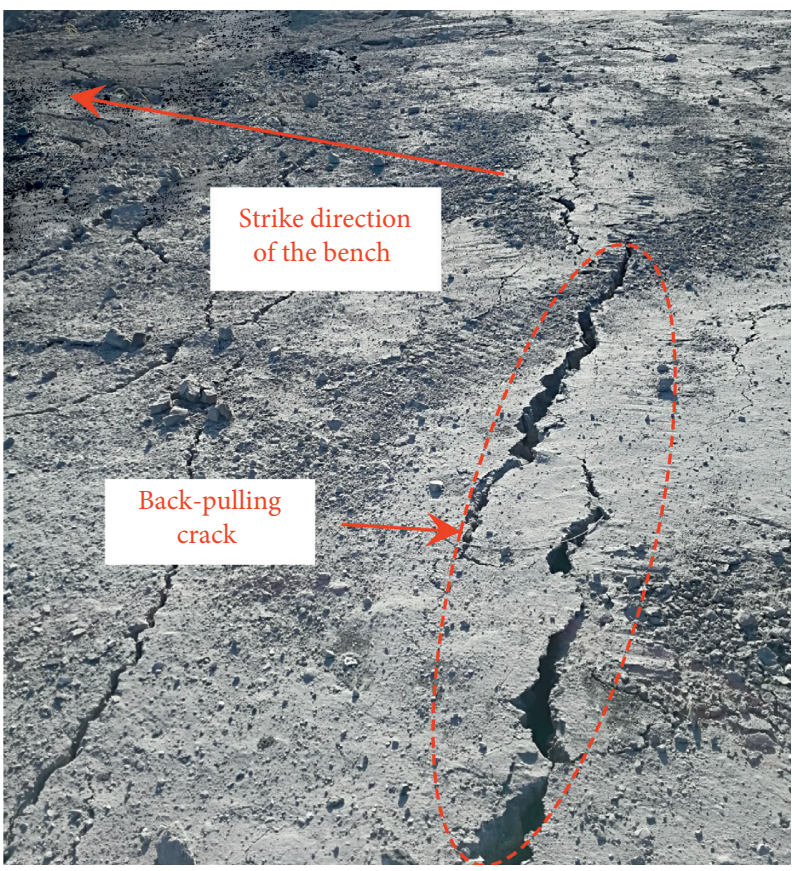

(a)

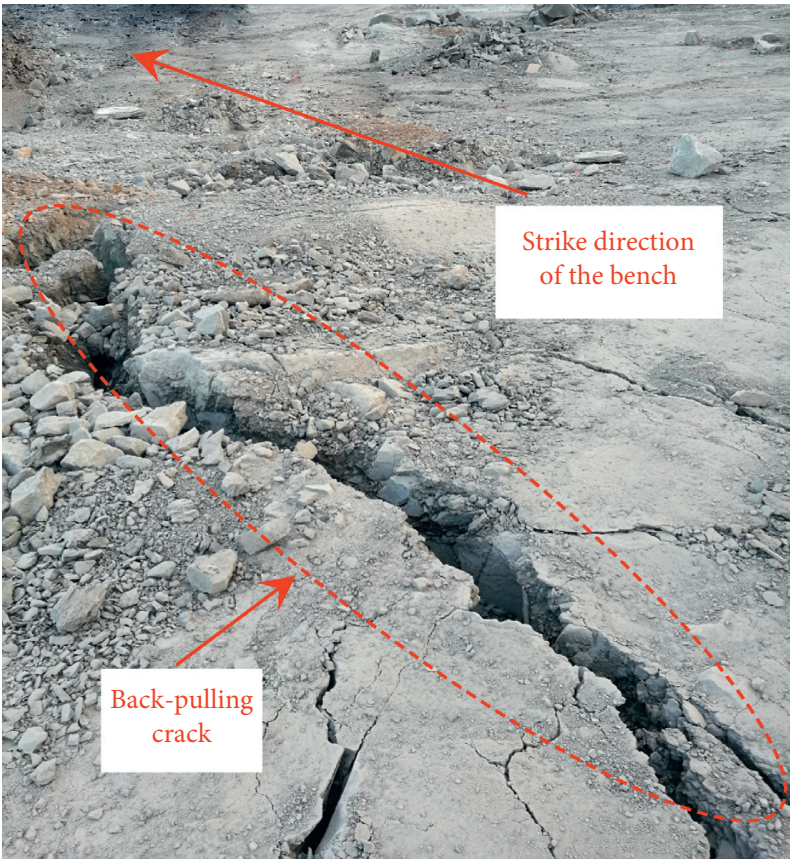

(b)

Figure 17: Comparative analysis of the back-pulling situation of the bench rock. (a) Back-pulling situation of the test group. (b) Backpulling situation of the control group. 
continuous charging and interval charging at the master weak layer. Figure 15(a) shows the layout of the explosion area. The delineated area was the blast hole area of the test group using interval charging, and the other parts were used as the control group using a continuous charging structure. Figure 15(b) shows the blasting process. There are few punching holes in the test group area. This was because the interval charging structure reduced the amount of charge mass, reduced unnecessary energy waste, and thus reduced the cost of blasting.

Figure 16(a) shows the crushing of the bench rock mass after blasting in the test group. It can be seen that the rock crushing was relatively uniform, which met the requirements of a desirable blasting effect. Figure 16(b) shows the result of the control group, which shows that due to uneven energy distribution of explosives, large rock masses were produced, and thus secondary crushing was needed, which increased the cost of rock crushing.

Figure 17(a) illustrates the back-pulling results of the bench for the test group. It can be seen that the degree of back-pulling was small, and it was distributed along the strike direction of the bench, which will not affect the subsequent drilling operations of bench blasting. Figure 17(b) is the control group, which shows that backpulling was more serious, and it was distributed along the dip direction of the bench that affected the follow-up operations.

\section{Conclusions}

This paper presented and studied the problems of the unsatisfactory blasting effects of rock mass containing weak interlayers. It further proposed the concept of the master weak interlayer and clarified the mechanistic influences of the weak interlayer on the bench blasting effect. On this basis, the bench master weak interlayer evaluation method was constructed in combination with the actual needs of the blasting project, which provided a reasonable basis for the design of the blasting blast hole of the interbedded stratum bench. The following conclusions were drawn:

(1) Numerical simulation experiments showed that the thickness and wave impedance of the weak interlayer in the rock mass were the main factors that affect the unwarranted bench blasting effect

(2) The main reason why a weak interlayer can affect the bench blasting effect was that it caused changes in the direction of the minimum resistance line and energy leaked from there. Interval charging will effectively alleviate this problem

(3) A mathematical method was used to construct an evaluation method that can quickly determine the master weak interlayer in a situation with multiple layers of weak interlayers, the reliability of which was validated using numerical experiments and field tests

The evaluation method of the master weak interlayer proposed in this paper was obtained by mathematical analysis through a small number of experimental results, and the reliability was verified in a typical soft and hard interbedded stratum bench. When this method was used to distinguish the master weak interlayer of a more complex rock mass bench, further improvements and validations will be needed to make it more amenable. In addition, the punching phenomenon of the control group in the field test might also be related to the packing quality, which requires more industrial testing for detailed comparative analysis.

\section{Data Availability}

The data presented in this study are available from the corresponding author upon a reasonable request.

\section{Conflicts of Interest}

The authors declare no conflicts of interest.

\section{Acknowledgments}

The authors would like to express their gratitude to GDEM Technology Beijing, Co., Ltd., for their support in numerical simulation. The research was financially supported by the Ph.D. Research Startup Fund of Xinjiang University (BS1902013), National Natural Science Foundation of China (51764050), and Accurate Delay Rock Breaking Mechanism and Key Technology Innovation Team (2020D14043).

\section{References}

[1] Y. Qi, N. Stern, and T. Wu, "China's post-coal growth," Nature Geoscience, vol. 9, no. 8, pp. 564-566, 2016.

[2] E. Tang and C. Peng, "A macro- and microeconomic analysis of coal production in China," Resources Policy, vol. 51, pp. 234-242, 2017.

[3] Y. Li, Y.-h. Chiu, and T.-Y. Lin, "Coal production efficiency and land destruction in China's coal mining industry," Resources Policy, vol. 63, Article ID 101449, 2019.

[4] Z. Shao, X. Jia, X. Zhong et al., "Detection, extinguishing, and monitoring of a coal fire in Xinjiang, China," Environmental Science and Pollution Research, vol. 25, no. 26, pp. 2660326616, 2018.

[5] Q. Zeng, L. Shen, and J. Yang, "Potential impacts of mining of super-thick coal seam on the local environment in arid Eastern Junggar coalfield, Xinjiang region, China," Environmental Earth Sciences, vol. 79, no. 4, pp. 1-15, 2020.

[6] H. Zhao, Y. Tian, and Q. Guo, "The slope creep law for a soft rock in an open-pit mine in the Gobi region of Xinjiang, China," International Journal of Coal Science \& Technology, vol. 7, no. 2, pp. 371-379, 2020.

[7] Y. J. Chen, Z. G. Chang, and J. F. Mao, "Blasting effect analysis of hole-by-hole millisecond minute difference initiation network along v-shaped oblique line," Electronic Journal of Geotechnical Engineering, vol. 20, no. 13, pp. 5833-5838, 2015.

[8] I. Metcalfe, C. B. Foster, S. A. Afonin et al., "Stratigraphy, biostratigraphy and C-isotopes of the ptdlp," Journal of Asian Earth Sciences, vol. 36, no. 6, pp. 503-520, 2009.

[9] Z. Leng, Y. Fan, and Q. Gao, "Evaluation and optimization of blasting approaches to reducing oversize boulders and toes in open-pit mine," International Journal of Mining Science and Technology, vol. 30, no. 3, pp. 373-380, 2020. 
[10] Y. J. Chen and X. C. Chen, "Analysis of blasting effect of nonhomogeneous ore body," Express Information of Mining Industry, vol. 427, pp. 22-25, 2005.

[11] Y. J. Chen, Z. G. Chang, and X. H. Chao, "Non-structural fracture blasting technique and case analysis of open pit coal mine in the arid area," in Proceedings of the Materials, Manufacturing Technology, Electronics and Information Science, pp. 121-130, Wuhan, China, October 2015.

[12] Y. J. Chen, Z. G. Chang, and F. Zhao, "Blasting methods for heterogeneous rocks in hillside open-pit mines with high and steep slopes," in Proceedings of the Global Conference on Polymer and Composite Materials, IOP Publishing, Wuhan, China, October 2017.

[13] M. Dong, F. Zhang, and M. Hu, "Study on the influence of anchorage angle on the anchorage effect of soft-hard interbedded toppling deformed rock mass," KSCE Journal of Civil Engineering, vol. 24, no. 8, pp. 2382-2392, 2020.

[14] G. Dongming and H. Da, "A complex rock topple-rock slide failure of an anaclinal rock slope in the Wu Gorge, Yangtze River, China," Engineering Geology, vol. 208, pp. 165-180, 2016.

[15] A. Zeinab and S. Mansour, "Distinct element modeling of the effect of Joint persistence on dynamic fracturing of jointed rock masses," Applied Mechanics and Materials, vol. 553, pp. 445-451, 2014.

[16] R. L. Ash, "Influence of geological discontinuities on rock blasting," Bachelor's thesis, University of Minnesota, Minneapolis, MN, USA, 1973.

[17] Y.-H. Jong and C.-I. Lee, "Influence of geological conditions on the powder factor for tunnel blasting," International Journal of Rock Mechanics and Mining Sciences, vol. 41, pp. 533-538, 2004.

[18] P. Kulatilake, W. Qiong, and T. Hudaverdi, "Mean particle size prediction in rock blast fragmentation using neural networks," Engineering Geology, vol. 114, no. 3, pp. 298-311, 2010.

[19] X. L. Song, J. C. Zhang, and X. B. Guo, "Influence of blasting on the properties of weak intercalation of a layered rock slope," International Journal of Minerals, Metallurgy and Materials, vol. 16, no. 1, Article ID 43657, 2009.

[20] X. L. Song, J. C. Zhang, and X. B. Guo, "Applied study on a quasi-static mechanical model for lamination of weak intercalation in layered rock slope caused by blasting," Explosion and Shock Waves, vol. 28, no. 6, pp. 565-571, 2009.

[21] S. Song, S. Li, L. Li et al., "Model test study on vibration blasting of large cross-section tunnel with small clearance in horizontal stratified surrounding rock," Tunnelling and Underground Space Technology, vol. 92, Article ID 103013, 2019.

[22] W. Sen, Z. Chunshun, and C. Yulin, "Dynamic compression characteristics of layered rock mass of significant strength changes in adjacent layers," Journal of Rock Mechanics and Geotechnical Engineering, vol. 12, no. 2, pp. 353-365, 2020.

[23] X. D. Kaide and H. Y. Yongqing, "Motion law of the layered filling solids under blasting," Metal Mine, vol. 388, pp. 32-35, 2008.

[24] J. C. Zhang, X. L. Song, and X. B. Guo, "Study on the deformation characters of weak intercalation in layered rock mass under deep-hole blasting," China Railway Science, vol. 29, no. 2, pp. 77-81, 2008.

[25] Q. J. Song, H. B. Li, and J. R. Li, "Influence of stratification on attenuation law of blasting vibration," Chinese Journal of Rock Mechanics and Engineering, vol. 31, no. 10, pp. 2103-2108, 2012.
[26] A. X. Xia, J. H. Zhang, and P. Zhang, "Blasting throwing direction of the layered rock in open-pit mine and its parameter optimization," Metal Mine, vol. 43, no. 3, pp. 40-43, 2014.

[27] Y. J. Wang, X. F. Chen, and T. H. Peng, "Analysis on influence of rock interlayer on blasting," Chinese Journal of Rock Mechanics and Engineering, vol. 8, pp. 1385-1387, 2004.

[28] M. Liu, J. Liu, M. Zhen et al., "A comprehensive evaluation method of bench blast performance in open-pit mine," Applied Sciences, vol. 10, no. 16, p. 5398, 2020.

[29] X.-N. Bui, H. Nguyen, H.-A. Le, H.-B. Bui, and N.-H. Do, "Prediction of blast-induced air over-pressure in open-pit mine: assessment of different artificial intelligence techniques," Natural Resources Research, vol. 29, no. 2, pp. 571-591, 2020.

[30] Y. Shang, H. Nguyen, and X.-N. Bui, "A novel artificial intelligence approach to predict blast-induced ground vibration in open-pit mines based on the firefly algorithm and artificial neural network," Natural Resources Research, vol. 29, no. 2, pp. 723-737, 2019. 